\title{
El debate energía y medio ambiente, tema de estudio en geografía
}

\author{
Alfredo Mingorance Jiménez
}

\begin{abstract}
RESUMEN ABSTRACT
El consumo de energía, el desarrollo de actividades industriales y el crecimiento demográfico han provocado numerosos problemas ambientales y de degradación espacial. En los países desarrollados, al menos, los modelos de desarrollo irrespetuosos con el patrimonio natural no tienen cabida porque deben aceptar politicas ambientales basadas en la protección de la biodiversidad y sujetas a evaluaciones de impacto. El compromiso, presente y futuro, no es otro que una actuación colectiva que permita la compatibilidad producción-consumo en el marco natural estable y libre de todo tipo de amenazas contaminantes y de destrucción paisajistica.

The consumption of energy, the development of industrial activities and the demographic growth have caused a number of environmental and space degrading problems. At least, in the developed countries, the development models which are disrespectful to the natural heritage are not possibie because these countries have to accept environmental policies based on the protection of the biodiversity and subject to impact testings. The present and future compromise is a joint action which allows for production-consumption compatibility in the stable natural framework and which is free of any kind of pollution and landscape destruction threats.
\end{abstract}

\section{INTRODUCCIÓN}

Nunca el hombre había provocado un deterioro en la naturaleza de tal magnitud como el que ha tenido lugar desde los años sesenta. Esto no quiere decir, que con anterioridad no hayan existido problemas medioambientales pero el desequilibrio se agrava cuando la recuperación no logra 
imponerse al deterioro, y los procesos antrópicos se tornan irreversibles, o bien se muestran como amenaza emergente, y ello sucede inexorablemente desde hace tres décadas.

Los cambios naturales o fluctuaciones actuan de manera reversible sobre los ecosistemas, en cualquier caso prevalece la regulación ecológica o adaptación a las modificaciones ambientales. Si el cambio se debe a las actuaciones del hombre la ruptura del equilibrio conlleva una alteración del ecosistema que desemboca en una grave degradación, a veces, irreparable. En este sentido es bien conocido el amplio catálogo de efectos agresivos derivado de vertidos, incendios forestales, roturaciones sobre la cubierta vegetal, que recuerda a lo expuesto por Lovelock en su teoría Gaia, la enfermedad del planeta y la ruptura del complejo equilibrio vital establecido desde hace millones de años y amenazado por el peligro de las intoxicaciones, contaminación de las aguas, gases de invernadero, lluvia ácida, reducción de la capa de ozono, desaparición de la flora y de la fauna, erosión de los suelos y desertización. En suma, impactos negativos sobre el medio y alteración de paisajes naturales constituídos por un conjunto de ecosistemas de componentes básicos, bióticos (especies) y abióticos (clima, topografía, hidrografía, suelos) que forman parte de un proceso dinámico de interacción entre los tres medios de la biosfera.

La restauración o reparación de espacios naturales es una ardua y dificil empresa que requiere tratamientos minuciosos para establecer la armonía hombre-medio y devolver la acción recíproca a las fuerzas primarias. Los proyectos ambientales de recuperación deben regirlos principios naturales de base ecológica, auxiliados por ciencias afines, la Geografía es una de ellas, y con un objetivo único, la reversibilidad del paisaje alterado. Por tanto, es necesario recuperar la pérdida de calidad del medio natural. En el medio físico los ecosistemas son víctimas de la degradación ambiental. ¿A qué obedece esta alarmante situación? posiblemente los modelos de desarrollo se apoyan de modo exagerado sobre la explotación, dudosamente racional, de los generosos recursos naturales. Los procesos de contaminación se suceden de manera ininterrumpida y los impactos ambientales negativos proliferan por mor de la industrialización y la urbanización generalizada. Sencillamente estamos inmersos en una crisis ambiental y echamos en falta una auténtica auctoritas política que obligue a un replanteamiento de los modelos de desarrollo implantados.

La presión social responde a una creciente sensibilidad que exige calidad de vida sinónimo de calidad ambiental, invariablemente unidas. Nuevas actividades económicas surgen con propósitos ambientales, y las tecnologías ecológicas proporcionan bienes y servicios bajo la supervisión 
internacional. El reciclado y la reutilización de los recursos sustituye al derroche y a la esquilmación, exponentes de una sociedad dilapidadora (Cifuentes Vega, 1997).

La sociedad consumista, que irrumpe a partir de los años sesenta, protagoniza el comienzo del deterioro medioambiental debido al consumo de masas, al industrialismo y a los nuevos estilos de vida que imponen una carga de productos altamente contaminantes caso de las pilas, aceites sintéticos y plásticos inorgánicos (Kostka y Gutiérrez, 1997). El gran reto del hombre actual es asumir la necesidad de garantizar la supervivencia de la especie humana, con su legado cultural, frente a los problemas ambientales al albor de la sociedad industrial y posindustrial. El hombre industrial somete a la naturaleza a un estado de presión permanente en el ejercicio de disponer de sus recursos, y para disiparlo está obligado a preservar y proteger el patrimonio natural mediante la conservación del medio físico y la interacción del medio social con su propio entorno.

La lucha entre progreso y medio ambiente sin deterioro o sostenible se ha convertido, desde hace algunas décadas, en una constante histórica. La disyuntiva no es otra que modelo convencional de desarrollo basado en el binomio producción-consumo con la consiguiente carga de contaminación y residuos, o modelo ecológico que respete la biodiversidad de especies, ahorro de recursos y con tecnología ambiental.

\section{MEDIO AMBIENTE, RENOVABILIDAD Y DESARROLLO}

La trilogía de intereses comunes medio ambiente, renovabilidad y desarrollo es el marco para el progreso de la sociedad actual. El medio ambiente o soporte ocupacional del hombre es un componente temporal sobre el que se patentiza la herencia cultural e histórica. El medio ambiente es por tanto un entorno vital donde conviven factores de variada índole, físicos, sociales, económicos, culturales, etc. La propia Real Academia de la Lengua define el medio ambiente como "elemento en que vive o se mueve una persona, animal o cosa" o "conjunto de circunstancias físicas, culturales, económicas y sociales que rodean a las personas y a los seres vivos". El medio ambiente desempeña tres funciones:

a) proveedor de recursos naturales, b) soporte de actividades y c) depósito de vertidos y residuos.

a) Es proveedor de bienes naturales por su escasez convertidos en recursos útiles de gran valor, sin precio de mercado, pero imprescindibles para el bienestar social o calidad de vida (ruido, silencio, estética paisa- 
jística, etc..). Los bienes económicos siempre están definidos por un valor conocido como precio de mercado. Si se aplica este criterio a los bienes de la naturaleza, hasta hace poco tiempo de escaso valor porque no tenían mercado, y se consideran los recursos naturales como bienes de uso directo, producción y consumo, y bienes de uso indirecto, beneficios funcionales propios de los ecosistemas de un bosque o de una cuenca hidrográfica, tienen un valor constituído en patrimonio ambiental. (Jiménez Herrero, 1997).

b) Es soporte de actividades susceptibles de modificación por el hombre pero los factores ambientales físicos, aire, clima, agua, suelo, flora, fauna y paisaje, y los factores ambientales sociales, hombre, bienes materiales, calidad de vida y patrimonio cultural hay que asegurarlos para mantener el equilibrio vital.

c) Es depósito de vertidos, tales como los efluentes líquidos y gaseosos, y los residuos reciclables e industriales no reciclables que contaminan a los tres medios, las sustancias sólidas, líquidas o gaseosas consideradas subproductos o residuos procedentes de un recurso utilizado, y como tal depósito dispone de una capacidad de asimilación o carga y por tanto de un nivel de saturación (Conesa Fernández-Vitora, 1997).

La energía es un recurso natural de caracteres no renovables y renovables. El caracter no renovable, agotable supone la extinción del recurso, caso de las energías fósiles contaminantes. Las energías renovables cada vez más presentes en el abastecimiento energético muestran una tendencia alcista en la contribución energética, porque la era del petróleo y del gas natural puede finalizar en un plazo históricamente corto, unos cien años. La dependencia del petróleo no está asegurada y el futuro es incierto. Un nuevo periodo energético entrará en escena, el de las energias no fósiles y el mundo desarrollado confiará, como lo ha hecho hasta ahora, en el abastecimiento de energía incluso a un alto coste.

Hasta la primera crisis energética en 1973 regia el principio de un mayor consumo de energía a un menor coste económico sin valorar el coste ambiental, en la actualidad ya no resulta válido este principio ni económica ni ambientalmente. Esta preocupación ligada al desarrollo se percibe en la Unión Europea por su alto grado de dependencia exterior en el suministro energético, 46,1\% en 1994, y aboga por un uso más eficiente de la energía destacando la importancia del ahorro. En los países con menor desarrollo en la medida que mejoren sus niveles de prosperidad se elevará el consumo y comenzarán a aflorar los problemas ambientales derivados del uso de energía a escala local y regional. Al mismo tiempo, en esta aldea global resulta inasequible suministrar energía al disperso mercado de pequeños gru- 
pos consumidores, y para satisfacer a este mercado las energías renovables están desempeñando una interesante función.

Un mundo desigual por economía y recursos naturales energéticos y no energéticos es el teatro de operaciones para unos pocos países ricos y una mayoría de países pobres. Esta realidad ambivalente llamada eufemísticamente primer mundo y tercer mundo es una sociedad de contrastes que se debate entre un alto consumo de energía, producción de bienes y servicios, y un consumo de energía mínimo vital, carente de bienes y servicios básicos para la dignidad humana. El mundo de la opulencia y el mundo de la privación, dos estilos de vida diametralmente opuestos. Modelos de desarrollo con un derroche de energía caso de América del Norte, y en menor medida Japón y Europa occidental, sin justificación en la sociedad posindustrial con más conciencia ambiental, más eficiente uso de la energía y un consumo menos intensivo de menor coste ambiental. En las antípodas, el modelo del Africa subsahariana con un bajo consumo de energía indicador de su miseria resignada a la esperanza, según las proyecciones, de incrementar el consumo a lo largo del próximo siglo.

Las desigualdades también aparecen en los balances energéticos o relación entre la producción y el consumo. En base a la balanza comercial energética, es decir, importaciones-exportaciones cabe distinguir tres grupos de paises:

- balances equilibrados al disponer estos países de fuentes de energía, caso de Estados Unidos y la ex Unión Soviética, o bien porque los intercambios entre fuentes de energía resultan compensados en paises ccmo Canadá o Australia, o bien porque tienen un consumo muy reducido debido a la pobreza general de muchos paises del Tercer Mundo.

- balances deficitarios, caso de paises de la Unión Europea, Japón y los Dragones Asiáticos.

- balances excedentarios, ejemplo, los países petroleros del Oriente Medio, países de la OPEP y China.

Actualmente un tercio de los habitantes del mundo, aproximadamente 2.000 millones, no disponen de electricidad y desconocen los servicios que ésta presta. Muchos de estos habitantes de las áreas rurales optan por ocupar los suburbios marginales de las ciudades y así participar del crecimiento de las grandes metrópolis tercermundistas con vagas expectativas de vida. Estas poblaciones de mínimos niveles de renta, excluídas del abastecimiento energético por la carestía de los combustibles fósiles, aguardan pacientemente sustanciales mejoras sociales si las energias re- 
novables adaptadas a la capacidad tecnológica y financiera de estos países penetran en sus vidas (Menéndez Pérez, 1997).

El alto crecimiento demográfico a lo largo del siglo, que previsiblemente se mantendrá en el próximo, desemboca en un conjunto de problemas sociales cada vez de mayor consideración medioambiental.

Evolución previsible de la población mundial

\begin{tabular}{|c|c|c|}
\hline & Regiones Desarrolladas & Regiones en Desarrollo \\
\hline Años & Millones Habitantes & Millones Habitantes \\
\hline 2000 & $1.100-1.500$ & 6.500 \\
\hline 2025 & " & 8.200 \\
\hline 2050 & “ & 9.100 \\
\hline 2100 & $"$ & 10.185 \\
\hline
\end{tabular}

Distribución de la población por áreas geográficas en el año 2100

\begin{tabular}{lrlll}
\hline \multicolumn{2}{c}{ Regiones Desarrolladas \% } & & \multicolumn{2}{l}{ Regiones en Desarrollo \% } \\
\hline Europa, ex -URSS, Japón y Oceanía & 10,4 & & Asia sin Japón & 48,2 \\
Estados Unidos y Canadá & 3,8 & Africa & 25,4 \\
& & América Latina & 12,2 \\
Total & 14,2 & Total & 85,8 \\
\hline
\end{tabular}

Fuente: Elaboración propia a partir de datos de T.M. Merrick "World Population in Transition» Population Bulletin, vol 41, núm 2, 1986.

Para atenuar los problemas demográficos y ambientales se debe reducir el consumo per cápita y mejorar la eficiencia y los rendimientos en la producción de energía, es decir, consumir menos energía calorífica para obtener energía eléctrica. A modo de ejemplo, para obtener $1 \mathrm{kwh}$ equivalente a 860 kilocalorías el consumo de energía en una central térmica es de 2.500 kilocalorías y el rendimiento es tan sólo del $34,4 \%$, por tanto se trata de mejorar el rendimiento con un menor consumo de energía.

El crecimiento económico expresado en satisfacer bienes y servicios está fundamentado en el consumo de recursos naturales, de energía y en el tratamiento de residuos generados. Las repercusiones sobre el medio, fruto de las actuaciones del hombre sobre el planeta, despiertan sobre todo en los países industrializados una creciente preocupación que con- 
verge en la mundialización de los problemas económicos y ambientales. Implica tanto a los países de centro, en mayor grado por las responsabilidades contraídas en su desarrollo económico, como a los países de la periferia que deben evitar, por insostenible, el modelo de industrialización convenido en el mundo desarrollado.

\section{CONTAMINACIÓN PAISAJISTIICA Y ACCIONES MEDIOAMBIENTALES}

La energía fósil es la principal fuente de contaminación de la biosfera, desencadenante de la contaminación global o problemas macroecológicos, efecto invernadero y cambio climático, y contaminación local o problemas microecológicos, contaminación del aire, agua y suelo.

Los problemas de contaminación global tienen su origen en las acciones antrópicas, tala e incendios de bosques, pastoreo abusivo, agujero de la capa de ozono afectada por compuestos orgánicos clorados y fluorados que dañan el ozono estratosférico, filtro de los rayos solares ultravioleta, $y$ los gases de efecto invernadero concentrados en la atmósfera que impiden que la radiación térmica infrarroja o calor emitido desde la Tierra se disperse por el medio atmosférico con el consiguiente recalentamiento de las capas bajas.

Los problemas de contaminación local principalmente atmosférica están asociados al consumo de energía en las actividades domésticas e industriales y en el transporte, que arrojan una amplia gama de contaminantes al aire: óxidos de nitrógeno, monóxido de carbono, compuestos orgánicos volátiles, metales pesados y compuestos sulfurosos. Los niveles de estos contaminantes varían por inmisión, límites máximos tolerables de un contaminante, aislado o asociado a otro, en la atmósfera y emisión, cantidad de contaminante en la atmósfera en un periodo determinado e indican el grado de deterioro y la magnitud de la alteración paisajística (Aguilar Fernández,1997). La contaminación en los paisajes urbanos de las grandes metrópolis está provocando una situación especialmente grave. Ejemplo, las megaciudades tercermundistas de elevado crecimiento demográfico como Calcuta, Bombay, El Cairo, México D.F. que requieren un tratamiento de urgencia para mejorar la planificación urbana, el transporte público y el uso de vectores energéticos más limpios.

La contaminación como efecto derivado de un proceso productivo no debe superar los niveles de absorción de los ecosistemas naturales. EI proceso productivo en términos de desarrollo sostenible combina procesos económicos y sociales con procesos ambientales y ecológicos (Jiménez 
Herrero, op. cit.). El crecimiento económico no es sinónimo de desarrollo ni de sociedad de bienestar, los fenómenos de contaminación urbano-industrial de los años setenta son ejemplo de la explotación irracional de los recursos y de la degradación de los paisajes naturales consecuencia de un modelo de producción-consumo depredador. El producto nacional bruto tan solo es un indicador económico material que enmascara el desarrollo y el bienestar socioeconómico, por ello la actividad económica debe adecuarse a la realidad ambiental y social para permitir un uso más racional de los recursos. La contaminación tiene unos costes ecológicos que hay que asumir en beneficio del propio entorno y exige poner fin al conflicto de intereses en juego. En la década de los ochenta ya no resultaba válido, por obsoleto, el principio de la década anterior de "quien contamina paga" y se abría paso el principio más real de "quien usa, paga", pues el beneficiario o usuario de un recurso o servicio ambiental tendrá que pagar por su utilización de acuerdo a un coste social de oportunidad ligado a su uso final. Si aplicamos este principio al orden internacional los paises del Tercer Mundo exportan sus riquezas naturales al mundo desarrollado a precios que no incluyen la mayoría de los costes ambientales (Jiménez Herrero, 1992). La ecocrisis que padecemos tiene un fundamento económico que afecta especialmente a los paises más débiles devorados por la deuda exterior que les atenaza, e incapaces de reajustes estructurales. De cualquier modo, ricos y pobres están inmersos en un proyecto común, el desarrollo sostenible o conjunción de intereses que interaccionan constantemente entre el sistema natural y social, es decir, entre los ecosistemas de un espacio y sus ocupantes obligando por igual a unos y a otros.

Una interpretación diferente del desarrollo sostenible entre el mundo rico y el mundo pobre impediría la confluencia de intereses en este planeta cada vez más globalizado y diverso. Las organizaciones internacionales, multinacionales, corporaciones industriales, gobiernos, grupos ecologistas y ciudadanos afrontan un planteamiento único, la protección y conservación de los espacios geográficos universales. El ejercicio de la política medioambiental exige poner freno a las actividades productivas nocivas para el medio, definiendo responsabilidades, grado de asunción de las mismas, bajo el establecimiento de órganos rectores y autoridades políticas que legislen en el marco jurídico sobre la tipificación del delito ambiental. Que prevalezca la valoración medioambiental sobre el criterio económico para no resignarse a la pérdida de calidad en el marco natural.

Por lo tanto, la declaración de impacto ambiental es un compromiso social que implica a todos los actores. El Real Decreto 1131/88 considera la Evaluación de Impacto Ambiental (EIA) como «el conjunto de estudios y sistemas técnicos que permiten estimar los efectos que la ejecución de 
un determinado proyecto, obra o actividad causa sobre el medio ambiente". El Reglamento de EIA recoge las actividades sometidas a evaluación ambiental de obligado cumplimiento, éstas son:

- Refinerías de petróleo bruto e instalaciones de gasificación y de licuefacción de al menos 500 toneladas de carbón de esquistos bituminosos.

- Centrales térmicas y otras instalaciones de combustión con potencia térmica de al menos $300 \mathrm{MW}$, así como centrales nucleares y otros reactores nucleares.

- Instalaciones de almacenamiento permanente o destinadas a eliminar residuos nucleares.

- Plantas siderúrgicas integrales

- Instalaciones destinadas a la extracción de amianto.

- Instalaciones químicas integradas.

- Construcción de autopistas, autovías, líneas de ferrocarril de largo recorrido y aeropuertos.

- Puertos comerciales, vías navegables, puertos de navegación interior y puertos deportivos.

- Instalaciones de eliminación de residuos tóxicos y peligrosos.

- Grandes presas.

- Primeras repoblaciones cuando entrañen riesgos de graves transformaciones ecológicas negativas.

- Extracción a cielo abierto de hulla, lignito u otros minerales.

La EIA es un procedimiento jurídico-administrativo válido como instrumento preventivo para alertar e impedir sobreexplotaciones en el entorno natural y social. Cualquier acción de índole económica o social supone una «alteración, positiva o negativa, producida por la introducción en el territorio de una determinada actividad la cual interviene sobre los factores que definen al mismo, en cuanto al medio físico, biótico y abiótico, y sobre las relaciones sociales y económicas del hombre con este medio" (Ruesga y Durán, 1995). La aplicación de una ElA puede impedir o al menos minimizar los efectos de las alteraciones debidas a la contaminación atmosférica y de los recursos hídricos, la degradación paisajística y del patrimonio cultural, la ruptura del equilibrio ecológico y de los ecosistemas, y el deterioro del medio, residuos y vertidos. Por otra parte, la ordenación territorial del espacio obliga actualmente a prevenir y corregir estas alteraciones, en el futuro las actuaciones procederán de la información y de la educación. 
La elaboración de una EIA comprende una serie de etapas o niveles de análisis. Comienza con una información meramente política que da paso a una planificación o informe general que abarca la localización de zonas aptas. En una segunda etapa o nivel de programación se realiza un anteproyecto, se trata de un análisis preliminar de incidencias con optimización de zonas aptas. El tercer nivel corresponde a la presentación del proyecto que engloba el Estudio de Impacto Ambiental (Es|A) y la elección de zonas. El EsIA, a partir de informes técnicos multidisciplinares, se basa en cuatro objetivos:

- análisis de las alteraciones medioambientales debidas a las actuaciones humanas.

- definición y evaluación del grado de afección en los medios físico, biótico y abiótico, social y económico.

- previsión de los efectos derivados del proyecto y valoración de su magnitud.

- aplicación de medidas correctoras para minimizar los impactos.

Los factores previsiblemente afectados por el proyecto son inventariados en los dos medios:

\section{Medio Físico}

- Geología

- Edafología

- Geomorfología

- Hidrología

- Hidrogeología

- Biogeografía, Climatología y Vegetación

- Fauna

Medio Social y Económico

Población

Variables sociológicas

Calidad de vida

Aspectos culturales

Renta

Empleo

Variables económicas

Precio del suelo

Sectores productivos

Estructura de la población activa

Variables urbanísticas

Uso y propiedad del suelo

Tipología y planeamiento 
Para recuperar el equilibrio natural las áreas degradadas necesitan controlar la erosión y restablecer la cubierta vegetal, mediante la aplicación de medidas correctoras que permitan la remodelación paisajística y la integración de este paisaje en su entorno.

Resultaría prolijo enumerar las actividades que causan incidencias ambientales. La minería a cielo abierto es un caso representativo de impacto ambiental por los efectos sobre la destrucción de hábitats, pérdida de recursos florísticos, de masa forestal, desaparición de suelo agropecuario, modificación de cursos fluviales y deterioro de la red subterránea de aguas, en conjunto, alteración y degradación del paisaje. Todas las actividades sometidas a EIA están obligadas a asumir la responsabilidad de:

- costes añadidos directos, tratamiento de residuos y su eliminación.

- costes ocultos o de gestión, seguros y riesgos, y

- costes futuros, sanciones, causas civiles y criminales.

Se trata, en cualquier caso, de llevar a cabo programas de restauración ambiental basados en el cumplimiento de la normativa sobre el medio ambiente, y a escala global de establecer una correcta planificación con tratamientos específicos en un contexto espacio-temporal de costes y beneficios.

\section{ENERGIA: CONTROVERSIA SOCIAL, ECONÓMICA Y MEDIOAMBIENTAL}

La energía es un tema de gran interés en los programas políticos que suscita controvertidos debates y discutidas propuestas de presente y futuro. Esta doble dimensión temporal expresa la complejidad del tema en el aspecto económico de producción-consumo, precios y organización de mercados, y en el aspecto político, estrategias a desarrollar por los paises productores-consumidores y las organizaciones empresariales participativas en los mercados. Con un coste añadido en el uso y aprovechamiento energético, el impacto medioambiental.

Desde una perspectiva geográfica el análisis de las relaciones de la energía es múltiple. Espaciales, localización de zonas de producción y zonas de consumo, balances energéticos, tasa de dependencia energética y sistemas de transporte. Económicas, desigualdades en las condiciones de explotación y costes de producción, características de los yacimientos, mercados de consumo y de abastecimiento, precios y flujos internacionales. Ambientales, contaminación en los tres medios, riesgos y accidentes. 
Sociales, un elevado nivel de vida lleva aparejado un mayor consumo energético, aire acondicionado para contrarrestar los sofocantes calores estivales y calefacción para mitigar los rigores invernales.

El hombre destaca el significado de la energía en sus modos de vida. La revolución industrial en realidad fue una revolución energética que introdujo trascendentales cambios en los sistemas de producción y en los transportes. La creciente demanda de energía está ligada al grado de desarrollo de una sociedad.

Evolución del consumo de energía y de la población mundial en el siglo $x x$

\begin{tabular}{lccccc}
\hline Años & 1910 & 1930 & 1950 & 1970 & 1990 \\
\hline Población mundial (millardos) & 1,70 & 2,02 & 2,51 & 3,62 & 5,32 \\
$\begin{array}{l}\text { Consumo energía tradicional } \\
\text { por persona (KW) }\end{array}$ & 0,30 & 0,28 & 0,27 & 0,27 & 0,28 \\
$\begin{array}{l}\text { Consumo energia industrial } \\
\text { por persona (KW) }\end{array}$ & 0,64 & 0,85 & 1,03 & 2,04 & 2,30 \\
Consumo mundial (Tw) & 1,60 & 2,28 & 3,26 & 8,36 & 13,73 \\
\hline
\end{tabular}

Fuente: Elaboración propia a partir de B. MĖRENNE-SCHOUMAKER (1997) "Géographie de l'énergie». Nathan Université, pág. 4.

El suministro de energía satisface los bienes y servicios demandados por los consumidores en un mundo conformado por desigualdades estructurales de riqueza y pobreza. El consumo de energía per cápita en el mundo desarrollado contrasta con la heterogénea realidad de un Tercer Mundo de marcadas diferencias socioeconómicas. Áreas urbanas que anhelan desarrollarse económica y socialmente, consumidoras de energía en transporte, industria y usos domésticos, que se abastecen de recursos energéticos propios, o bien recurren al mercado internacional de combustibles fósiles. Junto a comunidades rurales pobres o muy pobres sin energía eléctrica que cubren sus necesidades energéticas con leña y residuos (Menéndez Pérez, 1997, op.cit.).

Estos países periféricos del sistema global no son ajenos a la preocupación ambiental, pero al carecer de recursos financieros no acceden a una participación activa. Se escuchan con tibieza en los foros internacionales iniciativas para la creación de un fondo procedente de impuestos 
sobre las emisiones de $\mathrm{CO}_{2}$ destinado a proyectos energéticos para la instalación de plantas de energías renovables. Ejemplo, el aprovechamiento hidroeléctrico de los caudalosos ríos africanos. También se oyen voces que reclaman la condonación de la deuda exterior tercermundista, pesado lastre para el desarrollo, como contrapartida a la deuda ambiental contraída por el mundo desarrollado, y de este modo frenar posibles inestabilidades sociales y políticas propias de los países del subdesarrollo.

La generalización de las energías renovables, como apuesta de futuro, significaría un cambio cualitativo en el consumo energético. Todavía hoy la aportación de las renovables en el balance energético mundial es baja, $5 \%$ de la energía primaria del mundo desarrollado y aproximadamente el $10 \%$ en el mundo en desarrollo. Las energías fósiles cuestionadas por su coste ambiental y bajo la permanente amenaza de la agotabilidad se mantienen en espera de nuevas alternativas. Renovabilidad, energía nuclear de fisión y, a largo plazo, la fusión nuclear constituyen el abanico de probabilidades futuras. Las energías renovables tienen en cada país programas propios de $1+D$, en Estados Unidos los programas de biofuels los más novedosos, Japón se ha decantado por la solar fotovoltaica, la Unión Europea ha llevado a cabo varios programas: Valoren para subvencionar instalaciones, Altener para diseño e innovación, Joule y Thermie investigación básica con aplicaciones a la eólica. La energía nuclear de fisión con la rémora de los residuos radiactivos no augura un futuro esperanzador. La fusión nuclear es una de las pocas opciones energéticas a gran escala para el siglo xxı. La fusión es la fuente de energía del sol y las estrellas. En el núcleo del sol, a una temperatura de 10 a 15 millones de grados centígrados, el hidrógeno se convierte en helio y libera energía suficiente para hacer posible la vida en la Tierra. Para producir esta energía de fusión en un reactor termonuclear se hace fusionar dos isótopos del hidrógeno, el deuterio y el tritio a temperaturas superiores a 100 millones de grados alcanzando un cuarto estado de la materia, el plasma, y de este modo mediante un proceso de gran complejidad se reproduciría la fusión termonuclear con la consiguiente liberación de energía. El desafío de la fusión es la esperanza futura a la demanda de energía primaria para la segunda mitad del próximo siglo.

Según estimaciones la población mundial alcanzará los 10 mil millones de habitantes en los próximos cien años, y los recursos energéticos para satisfacer el consumo, probablemente el triple del actual, son:

- combustibles fósiles, principalmente carbón por la progresiva disminución de las reservas de gas y de petróleo.

- energía nuclear de fisión y de fusión. 
- renovables, hidráulica, solar fotovoltaica y térmica, eólica, biomasa, geotermia, mareas y olas.

Los recursos renovables, por sí solos, resultarían insuficientes para cubrir la demanda energética y la opción de la fusión pudiera ser aceptable por viabilidad económica, inagotabilidad (el agua de los océanos y de los lagos contiene hidrógeno pesado para millones de años) y seguridad medioambiental, al utilizar materiales de baja activación se reduce al mínimo la radiactividad y no origina contaminación atmosférica que provoque lluvia ácida o efecto invernadero.

En el XVII Congreso Mundial de la Energía celebrado recientemente en Estados Unidos se ha ratificado el incumplimiento de los acuerdos de Kioto sobre la reducción de las emisiones de $\mathrm{CO}_{2}$ por parte de algunos países de la Unión Europea, Alemania, Francia y Holanda. Se pone de manifiesto la dificil convergencia de intereses en el seno de los países comunitarios. Estos precedentes harán fracasar, por inasumible, cualquier propuesta dirigida a los países más débiles.

En resumen, el aprovisionamiento energético basado en la diversificación del abastecimiento cuenta con una creciente contribución de las renovables. Una deseada fusión nuclear, de lejano horizonte. Los combustibles fósiles en retroceso por el impacto ambiental y la agotabilidad, ante la atenta mirada de la energía nuclear que anhela mayor protagonismo en el suministro de energía en los años venideros. De cualquier manera, la especie humana garantizará la supervivencia si renuncia al desarrollo incontrolado y se compromete con el modelo sostenible.

\section{GRANDES ESCENARIOS, PAPEL DE LOS ACTORES Y ESTRATEGIAS DE FUTURO}

El consumo energético ha evolucionado en el tiempo y la demanda ha crecido ligada al desarrollo de los transportes, de la industria, de los servicios y del sector doméstico. En el sector industrial el consumo se ha estabilizado e incluso disminuído por la conjunción de varios factores, cambios tecnológicos, crisis de la industria pesada, ahorro y eficiencia por la implantación de tecnologías azanvadas. Los indicadores del consumo reflejan grandes diferencias entre los países por las desigualdades en el desarrollo. Por otra parte, los diferentes consumos en los paises desarrollados responden a determinadas estructuras económicas, hegemonía de la industria pesada gran consumidora de energía, caso de los paises de la 
Europa del Este y de la ex-URSS, frente a la potenciación de industrias ligeras de menor consumo en la mayoría de los países de la Unión Europea.

Los contrastes entre el mundo desarrollado y el mundo en desarrollo se mantienen y tienden a permanecer, todavía lejos de atenuar las diferencias.

\section{Consumo de energía en el mundo}

Consumo total de energía primaria en Millones de TEP

\begin{tabular}{|c|c|c|c|c|c|}
\hline Años & 1990 & 1995 & 1996 & $95 / 96 \%$ & Cuota del total \% \\
\hline EEUU & 1930,7 & 2069,1 & 2130,3 & 3,0 & 25,4 \\
\hline Canadá & 202,1 & 219,4 & 223,1 & 1,7 & 2,7 \\
\hline México & 99,0 & 107,6 & 111,5 & 3,7 & 1,3 \\
\hline América del Norte & 2231,8 & 2396,1 & 2464,9 & 2,9 & 29,4 \\
\hline América Central y del Sur & 270,2 & 324,8 & 341,4 & 5,1 & 4,1 \\
\hline Alemania & 351,8 & 334,5 & 345,0 & 3,1 & 4,1 \\
\hline Austria & 22,3 & 23,1 & 23,5 & 1,5 & 0,3 \\
\hline Bélgica y Luxemburgo & 55,8 & 57,1 & 60,2 & 5,4 & 0,7 \\
\hline Dinamarca & 16,8 & 19,9 & 23,7 & 19,2 & 0,3 \\
\hline España & 89,0 & 98,8 & 100,6 & 1,8 & 1,2 \\
\hline Finlandia & 22,3 & 21,9 & 23,2 & 6,1 & 0,3 \\
\hline Francia & 220,9 & 237,1 & 243,4 & 2,7 & 2,9 \\
\hline Grecia & 24,0 & 26,2 & 27,1 & 3,4 & 0,3 \\
\hline Holanda & 76,4 & 82,8 & 85,3 & 3,0 & 1,0 \\
\hline Irianda & 8,5 & 10,1 & 10,6 & 5,5 & 0,1 \\
\hline Italia & 151,5 & 155,6 & 156,8 & 0,8 & 1,9 \\
\hline Portugal & 14,7 & 17,8 & 16,9 & $-5,4$ & 0,2 \\
\hline R. Unido & 213,3 & 218,9 & 230,1 & 5,1 & 2,8 \\
\hline Suecia & 43,1 & 42,8 & 44,3 & 3,5 & 0,5 \\
\hline$U E$ & 1310,4 & 1346,6 & 1390,7 & 3,2 & 16,6 \\
\hline ex-URSS & 1397,8 & 946,5 & 923,2 & $-2,5$ & 11,0 \\
\hline O.Medio & 253,6 & 314,1 & 326,1 & 3,8 & 3,9 \\
\hline Africa & 212,0 & 241,6 & 252,4 & 4,5 & 3,0 \\
\hline China & 668,0 & 835,1 & 874,0 & 4,7 & 10,4 \\
\hline India & 179,6 & 230,1 & 246,7 & 7,2 & 3,0 \\
\hline Japón & 428,3 & 491,7 & 501,8 & 2,1 & 6,0 \\
\hline Asia & 1646,5 & 2077,4 & 2177,3 & 4,8 & 25,9 \\
\hline Oceanía & 100,8 & 108,3 & 110,5 & 2,0 & 1,4 \\
\hline Total Mundo & 7851,6 & 8137,3 & 8380,1 & 3,0 & 100 \\
\hline
\end{tabular}

Fuente: B.P. Statistical Review of World Energy. Junio 97. 
Consumo por habitante en kilogramos equivalentes de petróleo

\begin{tabular}{llll}
\hline Años & 1979 & 1985 & 1994 \\
\hline Norteamérica & 6,78 & 6,06 & 6,29 \\
EEUU & 8,31 & 7,43 & 7,82 \\
Canadá & 7,86 & 7,46 & 7,85 \\
México & 1,30 & 1,43 & 1,51 \\
América Latina & 0,77 & 0,72 & 0,81 \\
Europa Occid. & 3,26 & 3,14 & 3,25 \\
UE & 3,78 & 3,66 & 3,86 \\
Alemania & 4,77 & 4,64 & 4,13 \\
Reino Unido & 3,91 & 3,58 & 3,77 \\
Francia & 3,55 & 3,63 & 4,04 \\
Italia & 2,51 & 2,41 & 2,70 \\
España & 1,80 & 1,87 & 2,46 \\
Europa del Este & 3,80 & 4,06 & 2,88 \\
ex- URSS & 4,13 & 4,50 & 3,19 \\
Africa & 0,27 & 0,33 & 0,32 \\
Asia & 0,48 & 0,52 & 0,70 \\
China & 0,43 & 0,49 & 0,66 \\
Japón & 3,07 & 3,00 & 3,86 \\
Oriente Medio & 1,45 & 1,69 & 1,97 \\
Oceania & 4,40 & 4,48 & 5,16 \\
Total Mundo & 1,55 & 1,47 & 1,46 \\
\hline
\end{tabular}

Fuente: Agencia Internacional de Energía (AIE). Anuario estadístico, 1997.

El consumo de energía por habitante entre 1979 y 1994 ha disminuído en el mundo desarrollado, América del Norte y Europa Occcidental, por el ahorro y eficiencia energética, y ha crecido en el mismo periodo en los países en desarrollo, América Latina, Africa y Asia, aunque persisten desigualdades debidas a diferentes estadios de desarrollo. Europa del Este incluida ex-URSS ha disminuido el consumo de energía por habitante entre 1985 y 1994, etapa de transición hacia la economía de mercado, por un menor peso relativo de la industria pesada.

Las relaciones internacionales sobre producción, transformación y comercio de recursos energéticos se establecen sobre la base de una posición dominante. En la geopolítica de la energía alcanzar puestos hegemónicos supone establecer oligopolios económicos o bien disponer de una importante cobertura financiera que permita asumir riesgos frente a la competencia, incapaz de asumirlos. Los actores que intervienen en el ciclo energético son varios y operan en un escenario de intereses diferentes: productores, consumidores, transportistas y distribuidores, industrias de equipamiento energético y políticos (Mérenne-Schoumaker, 1997). 
Las empresas son actores de primer orden en materia de producción, de transporte, de distribución y de equipamiento energético, de capital público o privado, de mercado nacional o internacional. La intervención del Estado en el sector energético difiere según sean países productores o países consumidores. En los paises productores el intervencionismo estatal en el sector de la energía se ejerce a través de la propiedad del subsuelo y la concesión de explotaciones formalizadas de manera contractual y temporal. Entre los grandes países exportadores la nacionalización de los recursos es una práctica habitual, en otros casos el control corre a cargo de las empresas públicas. El cártel de la OPEP, países productores, surgió en 1960 para contrarrestar el poderío que en política de precios mantenían las «7 Hermanas». Este influyente cártel ha pasado de la imposición de precios y recaudaciones fiscales a un férreo dominio sobre la industria petrolera, desde 1967 controla la producción, y desde 1973 la explotación. Los países árabes de la OPEP manejan el petróleo como arma política desde el conflicto árabe-israelí, pero desde la década de los 80 la concurrencia de productores ajenos al mercado internacional y el cada vez más importante mercado spot o de ocasión, mercado por acuerdo político sin contratos y de entrega inmediata, origina tensiones internas en el seno de la OPEP. Para hacer frente a la nueva situación se establece entre los países miembros un sistema de reparto de cuotas y se reduce el precio oficial del petróleo para aproximarlo al precio spot. Desavenencias internas y pérdida de influencia ha llevado a la organización a reducir cuota de mercado, en 1974 su participación en la producción mundial era del $54 \%$ y en 1985 del $30 \%$, a partir de 1987 aumenta la producción. No hay que olvidar que la OPEP todavía está considerada como el principal actor del mercado petrolero con casi el $80 \%$ de las reservas mundiales (Mérenne-Schoumaker, op. cit.).

La política energética conjuga distintos factores: producción, consumo, dependencia exterior, garantía de abastecimiento, precios y equilibrio entre los aspectos económico, social y ambiental. Los países importadores de combustible fósiles, principalmente petróleo, han aplicado planes de ajuste dirigidos a disminuir la importación, y han puesto en práctica varias medidas: descentralizar las industrias muy consumidoras de energía, caso de la petroquímica, siderurgia y aluminio, hacia los países con recursos, potenciar el ahorro energético, subvencionar los recursos propios y sustituir el petróleo por otras fuentes de energía. Los stocks estratégicos obedecen a un triple objetivo, seguridad en el suministro, regulación y defensa frente a los oligopolios, sobre todo de la OPEP.

En 1974 la mayoria de los países de la OCDE han hecho causa común en la Agencia Internacional de la Energía (AIE) para protegerse de los 
conflictos entre países productores y consumidores, disminuir la dependencia del petróleo, establecer un mercado petrolero transparente y disponer de un fondo sobre el barril de petróleo destinado a la investigación de nuevas energías.

El mercado de la energía es un mercado sujeto a fluctuaciones permanentes por la variabilidad de la oferta y de la demanda. Los poderosos cárteles de productores y distribuidores influyen decisivamente en un escenario de intereses opuestos entre compradores y vendedores, pero siempre el precio final de la energía consumida es el resultado de un conjunto de costes técnicos y tasas fiscales. Además las variaciones de los flujos energéticos internacionales desde la primera gran crisis de la energía en 1973 hasta hoy repercuten en la mayor o menor estabilidad de los mercados. Por ejemplo, el gas natural ha aumentado su contribución al pasar de un $7 \%$ en 1973 a un $20 \%$ en 1996 , en este mismo periodo el petróleo ha visto descender su contribución pasando de un 55\% a un $43 \%$.

Debido al dinamismo del mercado internacional, la energía y la industria, como cualquier sector de producción, organizan sus propios mecanismos espaciales de distribución y localización de las actividades económicas, porque cada vez es menor la dependencia entre consumidores de recursos naturales y abastecimiento energético. El futuro es imprevisible y se escapa a la regulación. Las turbulencias y las tensiones de los mercados siempre dependerán de la variable oferta-demanda. La oferta ajustada a las valoraciones objetivas de las reservas y la demanda indicador de crecimiento demográfico y económico. Cualquier reflexión sobre el comportamiento de los grandes escenarios está basada en la evolución del crecimiento de la población y del consumo de energía por habitante. También el análisis de los principales componentes del sector energético, reservas, precios, tecnologias y problemas ambientales necesariamente se inserta en un inestable marco geopolítico, la ex-URSS y Oriente Medio disponen de la mayor parte de las reservas y de los recursos.

En conclusión,el consumo mundial de energía aumentará sobre todo en los paises que logren despegar del subdesarrollo y consigan incorporarse al heterogéneo grupo denominado en desarrollo. Los países que configuran la élite del desarrollo con menor intensidad energética minimizarán la preocupación medioambiental por el menor consumo de energía. Invariablemente unidas sociedad y tecnología, en espera de una acertada elección que ponga fin a un mundo polarizado entre riqueza y pobreza con graves desigualdades estructurales, deberán caminar por la senda de la solidaridad, y de este modo hacer coincidir el mayor crecimiento demográfico con los mayores niveles de crecimiento económico. Si este propó- 
sito no es alcanzable se tornará en seria amenaza para las sociedades del bienestar en el próximo siglo. Ingentes masas de población desposeídas reclamarían con vehemencia la entrada en el selecto club del desarrollo. De nada vale un mundo sostenible en lo ambiental si no llega la sostenibilidad a lo económico y a lo social.

\section{BIBLIOGRAFIA}

Agencia Internacional de la Energía (AIE). Anuario Estadístico, 1997.

AGUILAR FERNÁNDEZ, S. (1997): El reto del medio ambiente. Conflictos e intereses en la política medioambiental europea. Alianza. Madrid.

AZCÁRATE, B. y Mingorance, A. (1996): "La contribución de las energías renovables en la planificación energética española». Espacio, Tiempo y Forma, Serie VI, Geografía, t. 9, págs. 39/51. UNED, Madrid.

AzCÁRATE, B. y Mingorance, A. (1997): «Modelos de desarrollo y cambio climático». Espacio, Tiempo y Forma, Serie VI, Geografía, t. 10, págs. 33/50. UNED, Madrid.

Cifuentes Vega, P. (1997): «Análisis de la restauración medioambiental». En Peinado LoRCA, M. y SOBRINI SAGASETA, I.: Avances en evaluación de impacto ambiental y ecoauditoría. Trotta, Madrid, págs. 59/67.

CONESA FERNÁNDEZ-VITORA, V. (1997): “La evaluación de impacto ambiental y sus aplicaciones al desarrollo empresarial». En PEINADO LORCA, M. y SOBRINI SAGASETA, I.: Avances en evaluación de impacto ambiental y ecoauditoria. Trotta, Madrid, págs. 313/338.

ENERGÍA 1998. Foro Nuclear. Foro de la Industria Nuclear Española.

GONZALEZ, F. (1997): “El medio natural y el hombre». En SolER MANUEL, M.: Manual de gestión del medio ambiente. Ariel, Barcelona, págs. 133/141.

Jiménez HerRero, L. (1992). Medio Ambiente y Desarrollo Alternativo. lepala, Madrid.

JIMÉNEZ HERRERO, L. (1997): «Desarrollo sostenible y economía ecológica en la evaluación de impacto ambiental". En PEInAdo LoRCA, M. y Sobrini Sagaseta, I.: Avances en evaluación de impacto ambiental y ecoauditoría. Trotta, Madrid, págs. 93/126

KostKa FERnÁndez y GutiérRez BRITo (1997): "Consumo y medio ambiente". En Ballesteros, J. y PÉrez AdÁn, J.: Sociedad y Medio Ambiente. Trotta, Madrid, 83/102.

MENÉndez PÉREZ, E. (1997): Las energias renovables. Un enfoque político-ecológico. Los libros de la Catarata. Madrid.

MERENNE-SChOUMAKER, B. (1997): Géographie de l'énergie. Nathan Université.

MingorANCE JIMÉNEZ, A. (1995): «Viabilidad del desarrollo sostenible en un mundo solidario: consumo energético e impacto ambiental". Espacio, Tiempo y Forma. Serie VI, Geografía, t. 8, págs. 229/241. UNED, Madrid.

Ruesgas, S. y y DurÁn, G. (1995): Empresa y Medio Ambiente. Pirámide, Madrid. 


\title{
La incorporación al mercado laboral de la mujer inactiva: su distribución en España a finales del segundo milenio
}

\author{
Ma del PILAR Borderías URibeondo
}

\begin{abstract}
RESUMEN ABSTRACT
Desde el marco teórico de la

From the theoretical framework of Geografía, el artículo establece una inicial diferenciación espacial de la actividad femenina y de sus caracteristicas laborales, tras una reflexión sobre el cambio de la tradicional situación de cinactividad económica" de la mujer a lo largo de la década de los 90 y del análisis de los condicionantes que repercuten en su incorporación al mercado laboral: la edad, el estado civil, su nivel de instrucción y la discriminación Geography, the article establishes an initial spatial differentiation of the feminine activity and its labour characteristics, after a reflection over the change of woman's traditional role of "economic inactivity" along the 90 's, and of the analysis of the factors that have an effect on her joining the labour market: age, social state, level of studies and indirect discrimination.

indirecta.
\end{abstract}

\section{INTRODUCCIÓN}

La incorporación de las mujeres al mercado de trabajo ha constituido uno de los fenómenos más característicos de nuestro siglo en los países desarrollados, no obstante, las tasas de inactividad femenina en nuestro país siguen siendo muy elevadas. En España se ha pasado de unas tasas de inactividad femenina del $88,2 \%$ en 1950 al $64,93 \%$ en 1996 , quedando 
todavía por encima del porcentaje que se registra en los paises de la Unión Europea.

El incremento del número de mujeres que trabaja fuera del hogar en empleos remunerados no ha sido un fenómeno lineal ni homogéneo, sino que ha ido acorde con el desarrollo y la crisis industrial, y con diversos condicionantes sociales e ideológicos. Así, los períodos de mayor incorporación de las mujeres al trabajo han respondido a los ciclos económicos que se ha atravesado en cada momento, siendo una realidad la existencia de mano de obra potencial femenina que actúa de reserva, incorporándose o retirándose del mercado de trabajo en función de las oscilaciones del ciclo del empleo. Para un significativo grupo de mujeres aún puede seguir vigente aquella frase que apuntaban años atrás los grupos más radicales cuando señalaban que la mujer constituye un ejército de reserva laboral siendo "un asalariado potencialmente en paro cuando trabaja y un posible asalariado cuando permanece en el hogar".

De hecho, la integración plena de las mujeres en la economía sigue siendo una preocupación importante dada la significativa discriminación de la mujer en el ámbito laboral; buena prueba de ello es el esfuerzo efectuado, tanto por el Estado como por la Unión Europea, para desarrollar planes de igualdad que posibiliten y favorezcan su inserción laboral. En este sentido, se han realizado numerosos estudios sobre la participación de las mujeres en el mercado de trabajo, animados fundamentalmente por organismos internacionales como la ONU, la OIT, la OCDE y la UE, y por el impulso del movimiento de mujeres. En España el Instituto de la Mujer ha tenido un peso importante, al igual que los trabajos realizados en el marco de la Comunidad Económica Europea, alentados a través de la Comisión para la mujer y la Dirección General de Trabajo.

En las páginas que siguen, y a partir del análisis de parámetros fundamentales de carácter estructural, como son la actividad, ocupación, y paro, analizaremos la distribución en nuestro país de la situación de las mujeres en el mercado de trabajo.

\section{EVOLUCIÓN DE LA SITUACIÓN LABORAL DE LA MUJER ESPAÑOLA EN LA DÉCADA DE LOS 90}

La mujer española entra en la década de los noventa con un decidido propósito de incorporación al mercado laboral, puesto de manifiesto por el progresivo incremento de la tasa de actividad femenina, muy significativa 
si tenemos en cuenta que en tan sólo dieciseis años, desde 1980, esta tasa se ha incrementado en un $117.5 \%$, y en un $215.25 \%$ en relación con los años cincuenta. En cambio, las tasas de empleo y paro han tenido una evolución muy distinta, puesto que el empleo femenino, con sus altibajos, apenas ha crecido en esta década, y el paro femenino, muy superior al masculino, está por encima de la tasa de los años ochenta (25,5 en 1985, 29,1 en 1996), con una subida constante hasta 1994, en que comenzará su descenso con un año de retraso en relación con los hombres, desfase significativo que muestra la situación desfavorable en la que se encuentra la integración laboral de la mujer.

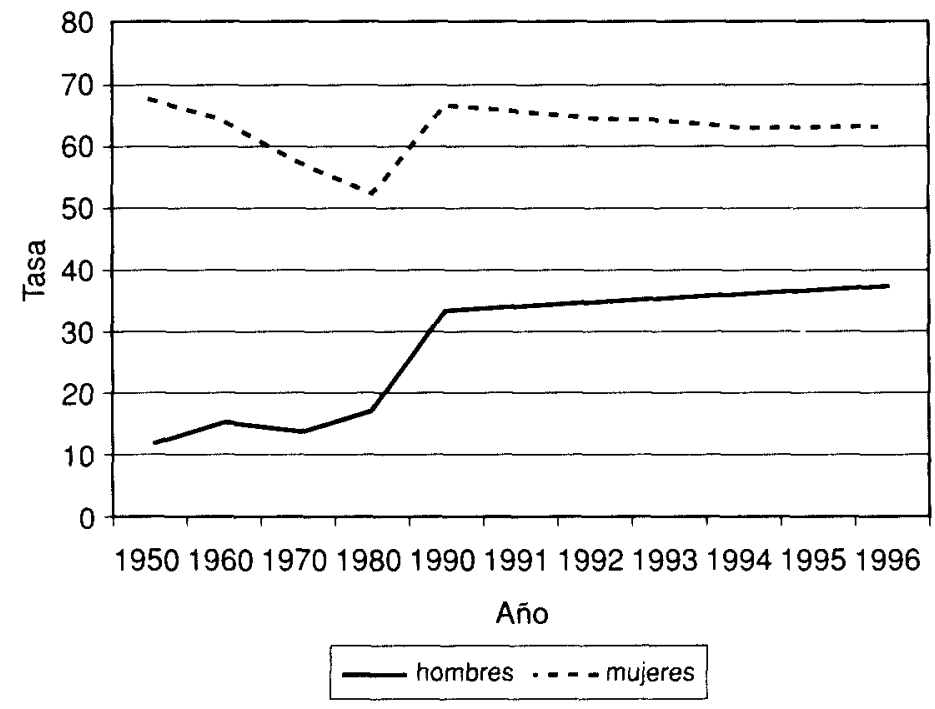

Gráfico 1. Evolución de la tasa de actividad por sexo.

A pesar de la tendencia de alza continuada de la tasa de actividad femenina, que contrasta con la masculina que ha descendido en los últimos diez años, la presencia de las mujeres en el mercado de trabajo sigue siendo muy inferior a la de los hombres, condicionada todavía por la distribución de papeles sociales según el género. En términos comparativos, también queda por debajo de los valores que se registran en la mayoria de los países de nuestro entorno económico, aunque resulta ser el país que mayor cambio ha registrado en su tasa de actividad desde 1985, año en que era el pais con menor actividad femenina (el 26,5, frente a Italia que le seguía con un 32,4 , y a una gran distancia de Dinamarca que tenía una 
tasa de 58,7). Actualmente su tasa del 37,2 queda a menor distancia de Dinamarca, que ha descendido al 45,2 , y está por encima de Italia $(36,9)$ y a la par que Grecia.

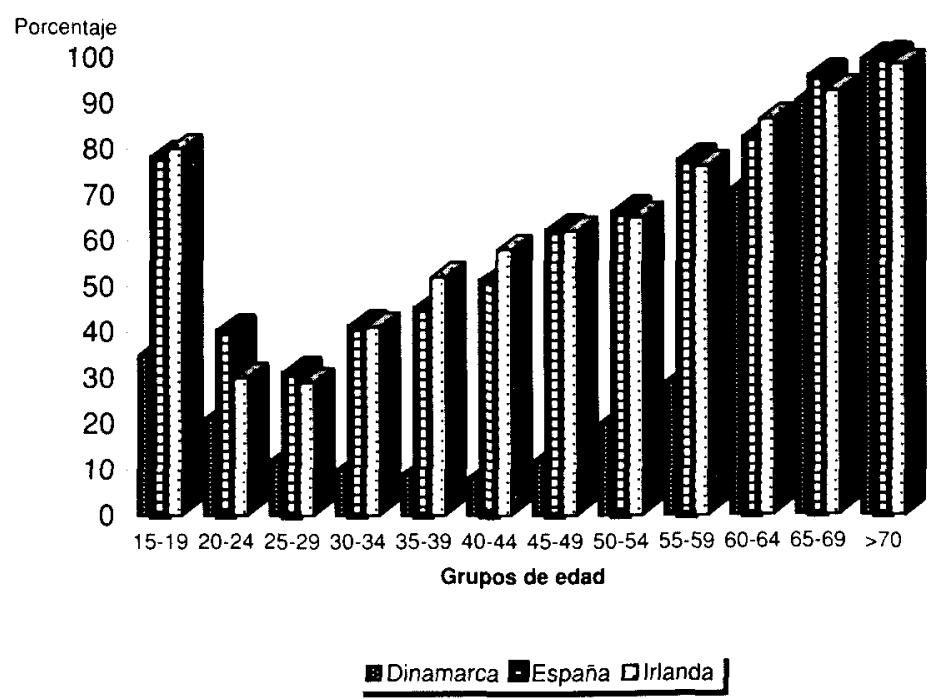

Gráfico 2. Inactividad femenina según la edad en la UE (contraste entre España y los países con mayor y menor tasa de inactividad).

En general, la inactividad sigue siendo importante en algunos países como el nuestro (gráfico $\mathrm{n}^{\circ} 2$ ), aunque con un manifiesto descenso en los grupos más jóvenes y con una evolución similar en todos los países, aunque en distinto grado, según los grupos de edad. La asignación social e ideológica del trabajo doméstico a las mujeres sigue creando dificultades para su incorporación laboral en muchos países, de hecho, la mujer se encuentra en el mercado de trabajo de una forma diferente al hombre, con unas expectativas y una jerarquía de valores diferentes. Por otro lado, si bien la mujer al tomar parte en el mercado de trabajo pasa a ser considerada como población activa, en realidad y para un importante grupo de ellas, la incorporación laboral no implica un descenso del número de mujeres que ejercen la producción doméstica a tiempo completo o «inactividad", sino más bien un aumento del número de mujeres que trabajan simultáneamente dentro y fuera del hogar.

Dentro de las situaciones de esta inactividad en España, es significativo el descenso de la dedicación a las labores del hogar, que ha pasado 
del $50 \%$ en 1984 al $34,07 \%$ en 1996 , de las cuales, además, el $75 \%$ son mujeres mayores de 39 años. Significativo es también que al mismo tiempo ha subido el número de mujeres estudiantes, con un porcentaje en 1996 del 10,29\%, superior al de los hombres que se sitúa en el $9 \%$. Alentadoras cifras para la incorporación laboral de la mujer basada, esencialmente, en el cambio de las nuevas generaciones.

Un aspecto que hay que tener en cuenta en el elevado porcentaje de inactividad que se observa, es la incidencia de la economía sumergida, en la que la mayoría de los empleos son ocupados por mujeres. Los índices de irregularidad laboral de las mujeres triplica a la de los hombres, y alrededor de la mitad de los ocupados en el mercado de trabajo irregular son mujeres. De hecho, en la pasada década se observó una creciente incorporación al mercado laboral sumergido de población oficialmente inactiva, sobre todo jóvenes y mujeres, estudiantes y amas de casa. Su actividad se centra sobre todo en formas de trabajo de tipo esporádico, a domicilio o a tiempo parcial, que les ofrece una amplia flexibilidad laboral, a los que se dirigen bien por necesidades familiares o por el deseo de una mayor autonomía frente a la institución familiar. Estos colectivos consideran estos trabajos como "ayudas" complementarias de los ingresos regulares, aunque, en su gran mayoría, acceden a estos empleos sumergidos o irregulares porque es lo único que se les ofrece.

Según un estudio del Ministerio de Economía y Hacienda, el índice de irregularidad podía alcanzar hasta el $60 \%$ en los servicios domésticos, actividad mayoritariamente ocupada por mujeres, un $42 \%$ en la confección, un $37,8 \%$ en la industria del calzado, un $34,5 \%$ en servicios personales, un $26,1 \%$ en la hostelería, etc. dando una media del $21,9 \%$ sobre el total de la ocupación.

\section{EDAD, ESTADO CIVIL Y NIVEL DE ESTUDIOS CONDICIONANTES DE LA INACTIVIDAD DE LA MUJER.}

Si bien en su conjunto hemos hablado de unas tasas de actividad femenina todavía bajas, hay que tener en cuenta la distribución de éstas, ya que la participación de la mujer en el mercado de trabajo no es homogénea debido a factores como la edad, el estado civil y los estudios realizados.

La edad constituye una de las variables que influyen en la presencia o ausencia de población activa femenina, dado que la tasa de actividad de las mujeres ha sido tradicionalmente muy sensible a partir de la edad de 
procreación. Las características de la actividad según sexo y edad en 1996 que nos muestra el cuadro $n^{\circ} 1$ evidencian la distinta composición y trayectoria de ambos sexos, pero también el cambio que está experimentando la situación de la mujer.

Cuadro 1. Contraste de las tasas de actividad, empleo y paro masculino y femenino según edad en 1991 y 1996.

\begin{tabular}{|c|c|c|c|c|c|c|c|c|c|}
\hline Edad & $\begin{array}{l}\text { T.A. } \\
\text { Mas. }\end{array}$ & $\begin{array}{l}\text { T.A. } \\
\text { Fem. }\end{array}$ & $\begin{array}{c}T . A . \\
\text { Fem. }\end{array}$ & $\begin{array}{l}\text { T.E. } \\
\text { Mas. }\end{array}$ & $\begin{array}{l}T . E . \\
\text { Fem. }\end{array}$ & $\begin{array}{l}\text { T.E. } \\
\text { Fem. }\end{array}$ & $\begin{array}{c}\text { T.P. } \\
\text { Mas. }\end{array}$ & $\begin{array}{l}\text { T.P. } \\
\text { Fem. }\end{array}$ & $\begin{array}{l}\text { T.P. } \\
\text { Fem. }\end{array}$ \\
\hline & 1996 & 1996 & 1991 & 1996 & 1996 & 1991 & 1996 & 1996 & 1991 \\
\hline 16 a 19 & 26.6 & 21.7 & 31.2 & 14.8 & 8.8 & 17.7 & 44.1 & 59.4 & 43.0 \\
\hline 20 a 24 & 63.1 & 56.5 & 61.4 & 41.8 & 30.7 & 37.9 & 33.7 & 45.6 & 38.2 \\
\hline 25 a 54 & 92.5 & 56.8 & 46.9 & 78.7 & 41.8 & 37.2 & 14.8 & 26.2 & 20.6 \\
\hline$>$ de 54 & 25.5 & 8.3 & 9.2 & 22.8 & 7.4 & 8.6 & 10.8 & 11.2 & 6.6 \\
\hline
\end{tabular}

Fuente: INE. CENSO/EPA.

La actividad masculina alcanza su máximo entre los 25 y los 54 años, tras los años de formación y servicio militar, mientras que la actividad femenina se estabiliza entre los 20 y 54 años, no experimentando el incremento masculino a partir de los 25 años, grupo en que cambia su estado civil, comienza su etapa de crianza, y empieza a desarrollar las funciones familiares que se le han asignado tradicionalmente. Pero si comparamos estos grupos con el año 1991, vemos que ha habido un importante cambio, al menos ya no desciende la actividad entre el grupo de 20-24 y 25-54 años sino que se mantiene, aunque por debajo de los valores de los hombres, que quedaban más próximos en el grupo de 16 a 19 años. Es pues notable el incremento experimentado por el grupo de 25-54 años, tal vez como resultado de la progresión de la integración a la actividad laboral de los grupos jóvenes de los últimos años. En general, a partir de los 35 años se produce cierta estabilización en la tasa de actividad femenina para registrar después de los 55 años una fuerte disminución, comparable a la de los hombres.

Precisamente, una de las principales diferencias entre el comportamiento laboral de hombres y mujeres estaba aquí, en la discontinuidad en la actividad que mostraban éstas en su período vital, explicada principalmente por la necesidad de atender a la familia. Por lo tanto, esta es una primera muestra de que la actitud de la mujer está cambiando en los años 90 , aunque la comparación de las tasas de empleo y paro respecto al otro 
sexo sigue mostrando sus graves problemas de inserción o de discriminación, pues, como ya mencionamos anteriormente, su tasa de empleo está muy por debajo y su tasa de paro muy por encima, al tiempo que ha bajado y ascendido respectivamente con relación a 1991.

Un hecho importante es el descenso de la actividad femenina experimentada por los grupos de 16 a 19 y de 20 a 24 años en 1996, puesto que ello supone un incremento de población estudiante en los niveles de estudios superiores, como lo corrobora el incremento de mujeres estudiantes dentro de la población inactiva.

Con respecto a la ocupación, los porcentajes según sexo y edad indican un mayor equilibrio hombre/mujer en los grupos de edad más bajos, experimentando una progresiva separación según aumenta la edad. Y no es precisamente la falta de formación lo que hace que la actividad de las mujeres esté tan marcada por el paro, ya que el valor del índice educativo de los parados es superior en las mujeres $(2,03$ frente a 1,84 en los hombres). Tampoco resulta favorable el hecho de que el sector servicios sea el que registre mayor porcentaje de paro (el $31 \%$ de los parados), puesto que en él trabaja el mayor porcentaje de mujeres, que representan además el $57,6 \%$ de parados del sector.

Estrechamente unido al factor edad, incide, como ya se ha señalado, el factor estado civil, por las connotaciones familiares que se asignan a la mujer. Resulta muy significativa la diferente tasa de actividad que se produce entre mujeres solteras y no solteras en relación con las casadas, de hecho las mujeres separadas-divorciadas, viudas jóvenes y solteras forman parte de la población activa de forma similar a la de los hombres mientras que las mujeres casadas son las que presentan tasas de actividad diferentes y muy inferiores. El gráfico no 3 nos permite ver cómo la población inactiva femenina casada tiene un progresivo incremento por grupos de edad mientras que en los hombres desciende a partir de la edad laboral.

A su vez, las diferencias de participación laboral de las mujeres según el estado civil se reduce o altera al relacionarlo con el nivel educativo, de modo que si bien se constata en general la incidencia en la menor disminución laboral que se produce en los grupos de mayor nivel educativo, resulta especialmente significativo en las mujeres casadas, que tienen mayor participación laboral al elevarse su nivel educativo. Esto refleja que la educación influye sobre la valoración ideológica de la tradicional división de funciones familiares, provocando actitudes favorables para su ruptura y para una mayor participación social de la mujer fuera del hogar. 


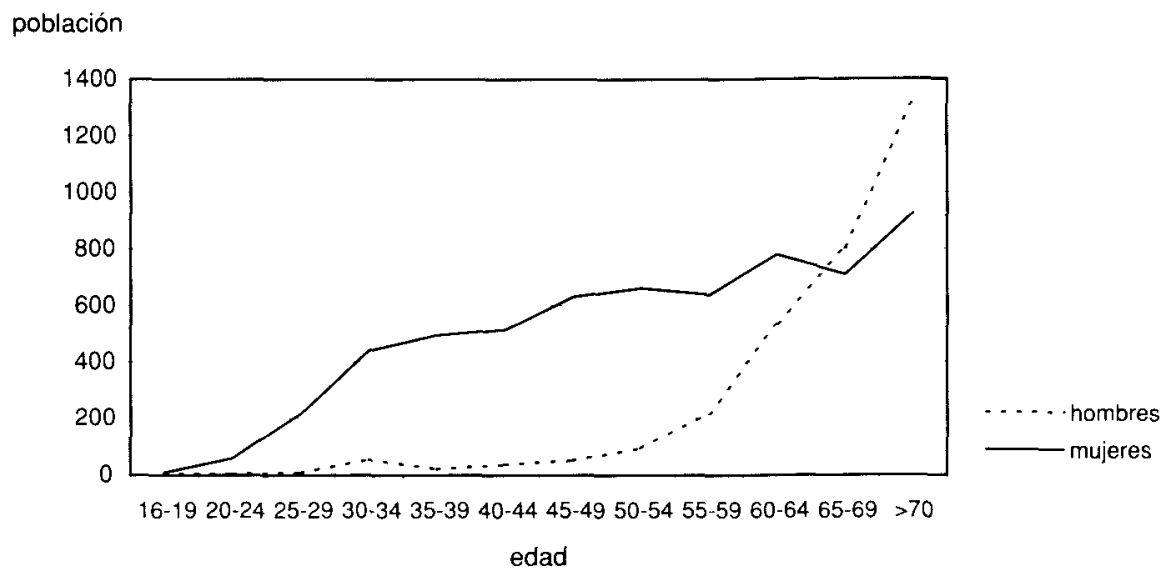

Gráfico 3. Evolución de la población inactiva casada según grupo de edad y sexo.

El acceso a la instrucción, unido a las campañas feministas y la toma de conciencia de los problemas profesionales son factores fundamentales en los cambios sociales en relación con la incorporación de la mujer al trabajo, de modo que la progresión hacia una mayor inserción sociolaboral de la mujer se debe en gran parte al mayor nivel de instrucción que va adquiriendo. Es notable el cambio experimentando en este sentido en los últimos años (gráficos $n^{\circ} 4$ y 5), reduciéndose la población femenina analfabeta y sin estudios a valores muy bajos en los grupos más jóvenes (por debajo de los 40 años en 1996), y alcanzando valores muy próximos a los hombres en los niveles superiores.

Este cambio en la capacitación y en la mentalidad, hace que, en general y para cada grupo de edad, el porcentaje de mujeres que trabaja sea superior cuanto mayor es el nivel de educación, excepto en los grupos de edad más bajos. De hecho se está incrementando la participación en los niveles de estudios medios y superiores, al tiempo que desciende o se estabiliza dicha participación en los niveles inferiores (sin estudios y primarios).

Según el índice educativo ponderado para los distintos niveles educativos $(E=3 P 1+2 P 2+1 P 3)$ siendo:

$$
\mathrm{Pt}
$$

$\mathrm{P1}$ : personas con estudios superiores.

P2: personas con estudios medios.

P3: personas con estudios primarios.

Pt: número total de personas de cada grupo de edad. 
La incorporación al mercado laboral de la mujer inactiva: su distribución en España...

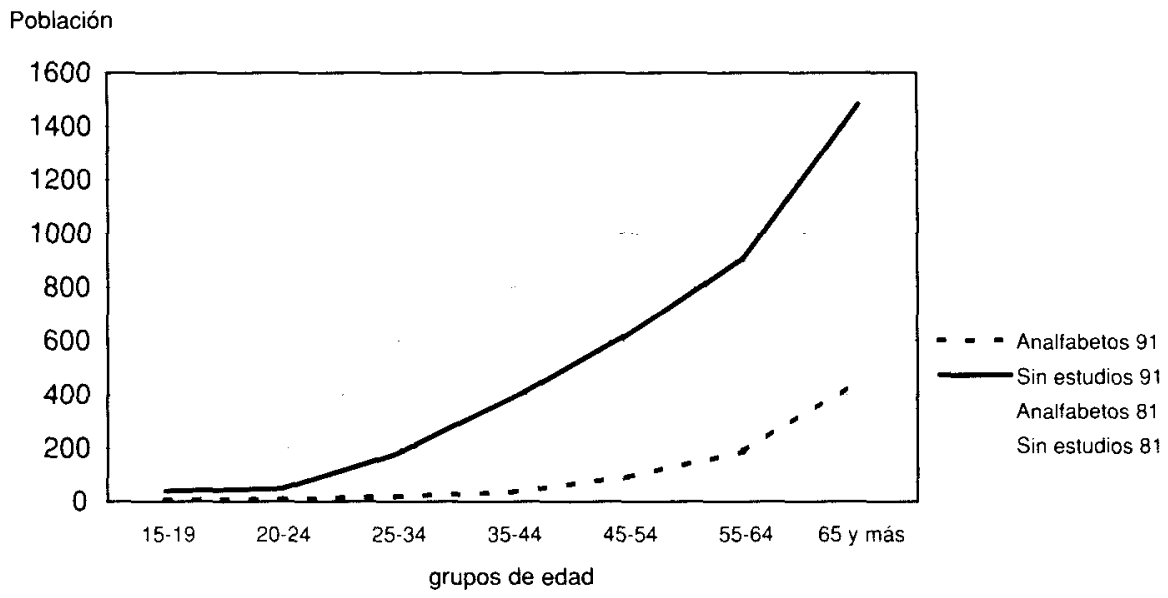

Gráfico 4. Mujeres con niveles de estudio inferiores según la edad.

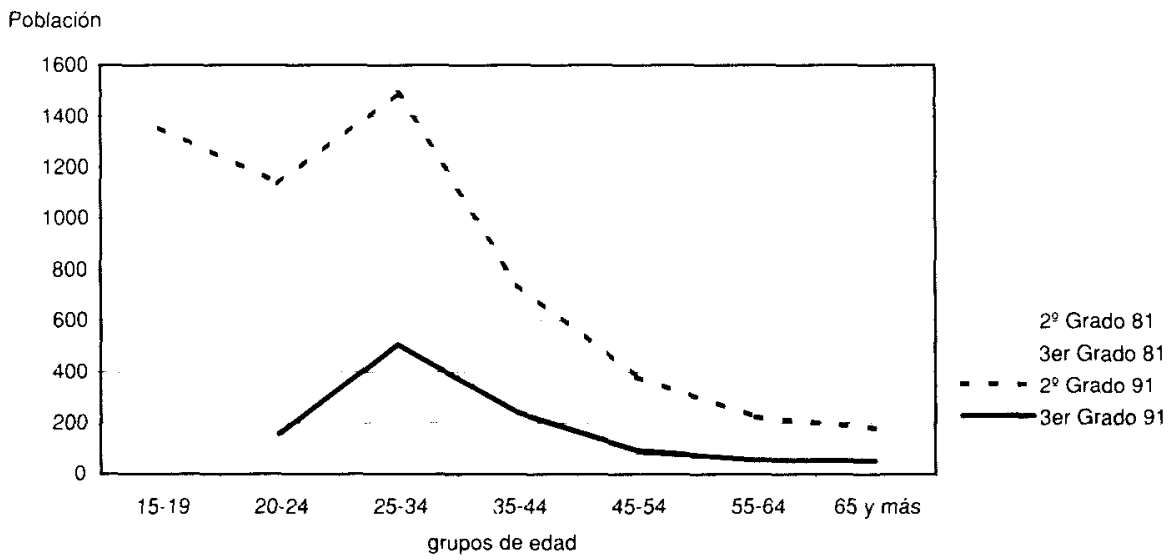

Gráfico 5. Mujeres con niveles de estudios superiores según la edad. 
Se obtienen los resultados del cuadro $n^{\circ} 2$. Según éste, el nivel educativo global es algo mayor en los hombres, pero si se analizan los resultados por grupos de edad encontramos que en los grupos más jóvenes el nivel educativo es superior en las mujeres, hasta el grupo de 30 años en 1991, lo que representa un avance con respecto a los datos del año 1983 en que el nivel educativo de la mujer resultaba inferior al de los hombres a partir del grupo de 25 años. A partir de esa edad el nivel educativo de la mujer es progresivamente más bajo. Lo cierto es que en el año 1991 la mujer ha alcanzado el nivel educativo medio de los hombres del año 1983 por lo que es de esperar que en no mucho tiempo llegue a equilibrarse. Podríamos hablar de un gran despegue educativo de la población, que se manifiesta especialmente en la mujer ya que partía de un nivel educativo inferior.

Cuadro 2. Indice educativo de la población total de 16 años y más por grupos de edad.

\begin{tabular}{lcccc}
\hline Grupo de edad & $\begin{array}{c}\text { Hombres } \\
1983\end{array}$ & $\begin{array}{c}\text { Hombres } \\
1991\end{array}$ & $\begin{array}{c}\text { Mujeres } \\
1983\end{array}$ & $\begin{array}{c}\text { Mujeres } \\
1991\end{array}$ \\
\hline De 15 a 19 & 1.73 & 1.74 & 1.76 & 1.80 \\
De 20 a 24 & 1.62 & 1.79 & 1.63 & 1.88 \\
De 25 a 29 & 1.49 & 1.81 & 1.43 & 1.88 \\
De 30 a 34 & 1.33 & 1.71 & 1.19 & 1.67 \\
De 35 a 39 & 1.20 & 1.54 & 1.06 & 1.43 \\
De 40 a 44 & 1.11 & 1.38 & 0.93 & 1.21 \\
De 45 a 49 & 0.99 & 1.23 & 0.81 & 1.03 \\
De 50 a 54 & 0.93 & 1.00 & 0.75 & 0.82 \\
De 55 a 59 & 0.89 & 0.87 & 0.72 & 0.70 \\
De 60 a 64 & 0.84 & 0.77 & 0.66 & 0.62 \\
De 65 a 69 & 0.79 & 0.71 & 0.57 & 0.56 \\
De 70 y más & 0.63 & 0.92 & 1.41 & 0.89 \\
Total & 1.17 & 1.29 & 0.99 & 1.17 \\
\hline
\end{tabular}

Fuente INE. Censo de población. EPA

Pero este elevado nivel educativo no resuelve las diferencias en el mercado laboral ya que, entre las personas que se encuentran en situación de demanda de empleo, la mayor diferencia porcentual entre sexos se da en los titulados medios y superiores, donde las mujeres demandantes de empleo representan el $70 \%$ y el $65 \%$ respectivamente. En cuanto a los demandantes de empleo con certificado de escolaridad, las mujeres representan el $44,2 \%$, y el $55,8 \%$ de los que tienen certificado de EGB. De 
hecho, las ocupaciones se jerarquizan teniendo en cuenta dos componentes, saber y responsabilidad, definida esta última como la "posesión de autoridad y capacidad de dirigir las actividades de otros", cualidades que todavía los empleadores asumen con dificultad en las mujeres.

\section{LA SEGREGACIÓN EN EL MERCADO DE TRABAJO}

Desde 1977, se ha realizado un importante esfuerzo para adaptar el ordenamiento jurídico español al principio de no discriminación por razón de sexo, recogido en varios artículos de la Constitución de 1978. Sin embargo, con frecuencia existe una gran diferencia entre las disposiciones legales y la práctica, por lo que se ha realizado un importante esfuerzo para establecer políticas específicas que integren a las mujeres en todos los ámbitos de la vida privada y pública.

La discriminación de la mujer en el mercado de trabajo sigue siendo una realidad que se pone de manifiesto en la diferencia entre ambos sexos en el grado de ocupación laboral, en el tipo de contrato, en el perfil laboral, o, lo que es más significativo, en el distinto sueldo que obtienen con los mismos estudios o con las mismas profesiones.

Evidentemente las mujeres tienen mayores dificultades para su contratación laboral. Si analizamos la información aportada por el INEM, resulta que de los cursos gestionados por este organismo en los niveles de formación ocupacional dentro del Plan FIP (Formación e Inserción Profesional) en 1996, a pesar de que el porcentaje de mujeres formadas es ligeramente superior al de los hombres (51\%-49\% respectivamente) su inserción laboral es menor (un $67,7 \%$ en el caso de los hombres y de un $57,2 \%$ en el de las mujeres). Solamente en el grupo de edad de menores de 20 años la tasa de inserción es ligeramente superior en las mujeres, en el resto, de 20 a 44 años la inserción femenina se distancia de la masculina según aumenta la edad. Es de destacar que en los grupos de mayores de 44 años no ha habido ninguna mujer en formación en el año 96, lo que nos está indicando el límite en el que se está revitalizando la incorporación de la mujer.

Pero además de las dificultades en la contratación, es frecuente que exista a su vez una significativa diferencia en cuanto al tipo de contrato. Las mujeres superan a los hombres en los siguientes tipos de contratos: tiempo parcial, interinidad, contratos en prácticas, y jóvenes menores de 25 años. Por el contrario, en los contratos indefinidos quedan por debajo $(33,96 \%)$ de estos. Si tenemos en cuenta que es la incorporación laboral 
de la mujer joven la que más incidencia está teniendo, tampoco le resultan favorables las estadísticas del tipo de contratos a menores de 25 años, en los cuales superan el $30 \%$ de los contratos eventuales, lanzamiento de nueva actividad y tiempo parcial; en cuanto a los de interinidad, obra y servicio, tiempo parcial indefinido y minusválidos se sitúan en torno al $28 \%$.

La concentración del empleo femenino es otro indicativo diferenciador. Tradicionalmente se explicaba que la falta de formación de la mujer era el impedimento para la diversificación, poniéndose como ejemplo de ello las pocas mujeres que se dirigían a la enseñanza técnica. Hoy día esta situación ha variado, en las nuevas generaciones, con relación a los niveles medios y superiores de estudios, equilibrándose los géneros en la asistencia a las aulas de carreras técnicas tradicionalmente ocupadas por los hombres, a pesar de lo cual sigue produciéndose el mismo fenómeno.

Si observamos los porcentajes de representación femenina en distintas ocupaciones, apreciamos inmediatamente la existencia de empleos y categorías femeninas y masculinos con prácticamente nula presencia de trabajadores del otro sexo. En el cuadro $n^{\circ} 6$ se relacionan las ocupaciones que han tenido más contrataciones en 1996, según datos del INEM, con la demanda femenina en cada ocupación y los índices de representación femenina en cada ocupación (la OCDE valora la segregación a través de los "índices de representación femenina" (IRF), definidos como relaciones entre los porcentajes de participación de la mujer en un empleo dado respecto a la participación de la mujer en el empleo total). A partir de estos datos podemos ver:

a) La discriminación que hace de sí misma la mujer, seleccionando determinadas profesiones a través de su demanda de trabajo. Así profesiones como camarera, mujer de limpieza, auxiliar de clínica, ATS, azafata, telefonista, o dependiente de comercio, tienen una demanda de mujeres superior al $85 \%$ del total de la demanda. Esto indica, por un lado, que sigue pesando todavía el tradicional concepto de tareas femeninas: sanidad, enseñanza, limpieza, etc., que llevan a que la mayoría de las mujeres ejerzan su actividad en un limitado número de empleos, normalmente relacionados con dicho concepto.

En sentido inverso, no suponen ni el $5 \%$ de la demanda en profesiones como albañil, electricista, conductor de camión, o pintor decorador de edificios.

De ello resulta que es en el sector servicios donde predominantemente realizan su trabajo las mujeres (el $79,73 \%$ ), quedando infrarrepresentadas en los otros sectores de actividad: un $12,78 \%$ en industria, un $6,23 \%$ en agricultura, y un $1,24 \%$ en la construcción. 
b) La discriminación de la contratación por sexo, ya que el porcentaje de las contrataciones por sexos no es acorde con la demanda, puesto que mientras que el $52,68 \%$ de los demandantes de empleo eran mujeres, los contratos de éstas sólo supusieron el $37,80 \%$ del total. Observando las características de las ocupaciones con mayor número de personas contratadas, hay casos en que se establece una discordancia entre los demandantes y los contratados en perjuicio de las mujeres, en el sentido de que existiendo mayor porcentaje de demandantes femeninas, los contratos se han dado a un porcentaje muy superior de hombres, este es el caso por ejemplo del trabajador agrícola (52\% de mujeres demandantes y el $64,4 \%$ de los contratos a hombres); dependiente de comercio al por menor (frente al $85,3 \%$ de las demandas femeninas sólo han obtenido el $67.7 \%$ de los contratos); mozo-mujer de limpieza (95,5\% de la demanda y el $81,6 \%$ de los contratos); cocinero $(61,8 \%$ de la demanda y el $51,22 \%$ de los contratos); profesor de educación general básica $(84,7 \%$ de la demanda y $66,01 \%$ de los contratos); médico $(64,8 \%$ de la demanda y $55,3 \%$ de los contratos); o pinche de cocina ( $79,7 \%$ de la demanda y $62,9 \%$ de los contratos). Como podemos ver, esta situación se produce en toda la gama de los niveles de estudios.

Este resultado plantea el interrogante de la existencia de una discriminación indirecta (ya que la discriminación directa queda resuelta legalmente) a través de mecanismos del mercado de trabajo que pesan de forma diferente sobre hombres y mujeres. Esta noción de discriminación indirecta es compleja en la medida en que supone procesos que parten de situaciones aparentemente neutras y conducen a resultados aparentemente neutros. Así, determinados requisitos profesionales de acceso a un puesto de trabajo impuestos por el empleador, o las condiciones del empleo que tienen un impacto negativo desproporcionado sobre las personas de un sexo o de un estado familiar determinado, son ejemplos que llevan a estas situaciones. Así, por ejemplo, aspectos como la atención a la familia supone una menor movilidad y flexibilidad laboral, tanto geográfica como horaria, y una disponibilidad laboral inferior a la de los hombres, sobre todo en el caso de los ejecutivos a los que las empresas exigen una dedicación incondicional.

Los salarios siguen la misma tónica discriminatoria. Si observamos los gráficos $n^{\circ} 6$ y 7 , según el nivel de estudios realizados, las mujeres tienen unos sueldos medios inferiores a los hombres en todos los casos, con valores que oscilan entre el $31,5 \%$ y el $43,3 \%$ menos; y lo mismo ocurre si comparamos los salarios según los grupos profesionales, en todos los casos, excepto construcción (donde su representación es mínima), son menores, oscilando entre el $20,2 \%$ y el $38,9 \%$. 
Cuadro 3. Índice de representación femenina de las ocupaciones que han tenido más contrataciones en 1996.

\begin{tabular}{|c|c|c|c|c|}
\hline Ocupaciones & (1) & (2) & (3) & (4) \\
\hline Trabajador agrícola & 12.43 & 52.0 & 0.29 & 0.35 \\
\hline Peón & 11.20 & 38.2 & 0.17 & 0.22 \\
\hline Albañil & 6.49 & 0.8 & 0.008 & 0.01 \\
\hline Empleado administrativo & 5.94 & 74.9 & 0.67 & 0.68 \\
\hline Dependiente comercio & 5.84 & 85.3 & 0.66 & 0.67 \\
\hline Camarero & 5.25 & 32.5 & 0.33 & 0.37 \\
\hline Mozo-mujer limpieza & 5.12 & 95.5 & 0.83 & 0.81 \\
\hline Peón construcción & 3.98 & 1.2 & 0.02 & 0.09 \\
\hline Cargador almacén & 1.75 & 7.7 & & 0.16 \\
\hline Cocinero & 1.41 & 61.8 & 0.53 & 0.51 \\
\hline Conductor camión & 1.37 & 0.7 & 0.007 & 0.01 \\
\hline Auxiliar clínica & 1.15 & 92.2 & 0.87 & 0.86 \\
\hline Peón ind. alimentarias & 1.15 & 76.5 & 0.46 & 0.62 \\
\hline Peón siderometalurgia & 0.90 & 23.7 & 0.06 & 0.12 \\
\hline ATS & 0.87 & 85.1 & 0.78 & 0.83 \\
\hline Electricista & 0.87 & 1.2 & 0.01 & 0.02 \\
\hline Repartidor a domicilio & 0.82 & 6.1 & 0.08 & 0.20 \\
\hline Camarero/a-hostelería & 0.77 & 98.2 & 0.95 & 0.94 \\
\hline Cajero comercio & 0.72 & 82.4 & 0.88 & 0.89 \\
\hline Profesor EGB & 0.71 & 84.7 & 0.69 & 0.66 \\
\hline Vigilante & 0.59 & 14.6 & 0.06 & 0.16 \\
\hline Cosedor máquina industrial & 0.58 & 97.8 & 0.91 & 0.91 \\
\hline Estibador & 0.56 & 2.4 & & 0.005 \\
\hline Médico medicina general & 0.54 & 64.8 & & 0.55 \\
\hline Agente de comercio & 0.54 & 16.1 & & 0.34 \\
\hline Encofrador & 0.54 & 0.3 & 0.009 & 0.005 \\
\hline Cartero & 0.53 & 67.0 & & 0.58 \\
\hline Entrevistador & 0.51 & 65.7 & & 0.69 \\
\hline Pintor decorador edificios & 0.48 & 2.2 & & 0.01 \\
\hline Carpintero & 0.47 & 5.5 & 0.05 & 0.04 \\
\hline Embalador a mano & 0.44 & 82.2 & 0.84 & 0.81 \\
\hline Azafata de información & 0.43 & 96.4 & & 0.91 \\
\hline Telefonista & 0.39 & 93.1 & & 0.85 \\
\hline TOTAL & 75.34 & - & & - \\
\hline
\end{tabular}

(1) Porcentaje de contratación respecto al total de contratos realizados. (2) Porcentaje de demanda femenina en cada ocupación. (3) Índice de representación femenina en cada ocupación en 1992. (4) Índice de representación femenina en cada ocupación en 1996.

Fuente: INEM. Observatorio ocupacional. Elaboración propia.

La situación profesional va mejorando aunque todavia las mujeres representan el $60,2 \%$ de los trabajos de ayuda familiar (lo que está demostrando una elevada dependencia social), ocupan un $44 \%$ del empleo en el 
sector público, un $33 \%$ de los asalariados del sector privado, un $28,1 \%$ de los miembros de cooperativas, y sólo un $26,28 \%$ del total de empresarios. Por otro lado, la marginalidad es otra característica de un buen número de mujeres que tienen algún trabajo pero que con frecuencia son oficialmente inactivas. La cifra de ocupados marginales estimados por la EPA tiene un elevado porcentaje en las mujeres, y, según la encuesta de condiciones de vida y trabajo, una de cada tres mujeres ocupadas está en situación irregular.

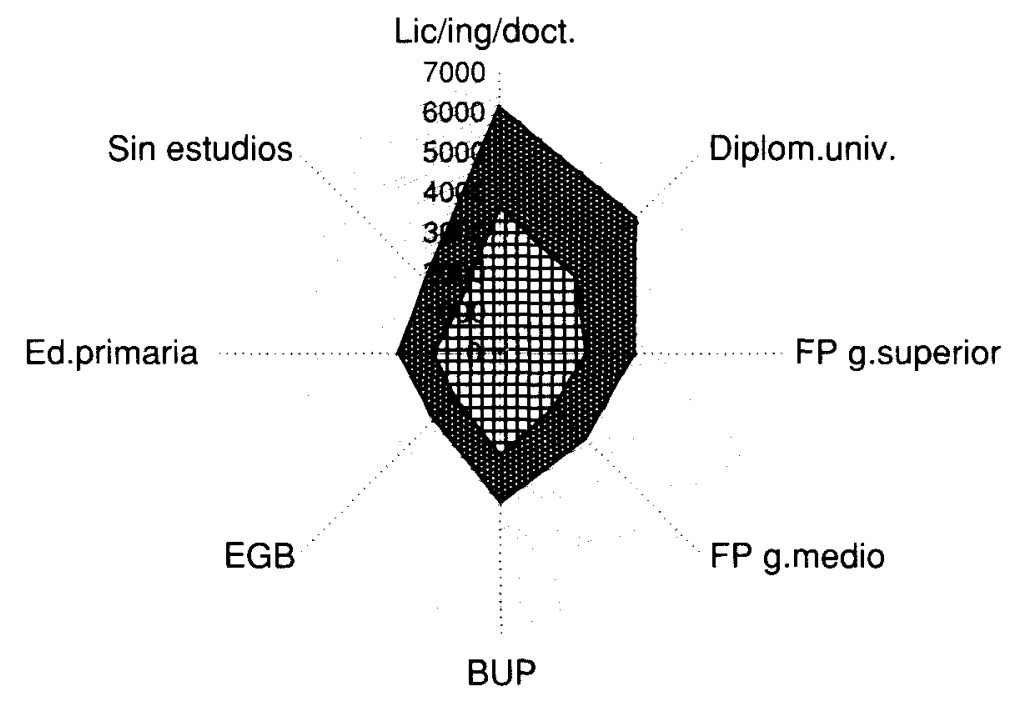

Dhombres Emujeres

Gráfico 6. Sueldo anual por trabajador según nivel de estudios.

En definitiva, para que las mujeres cuenten realmente con una igualdad de oportunidades, además de perfeccionar y completar el desarrollo normativo del principio de igualdad, hace falta seguir desarrollando actitudes, comportamientos y estructuras sociales que permitan a las mujeres su participación activa en todos los campos de la actividad económica, política y social.

Teniendo en cuenta las caracteristicas de la mujer activa mencionadas hasta aqui, podríamos diferenciar dos grupos: el de las «mujeres cualificadas» y el de las «mujeres sin cualificar», subdividiéndose este último 


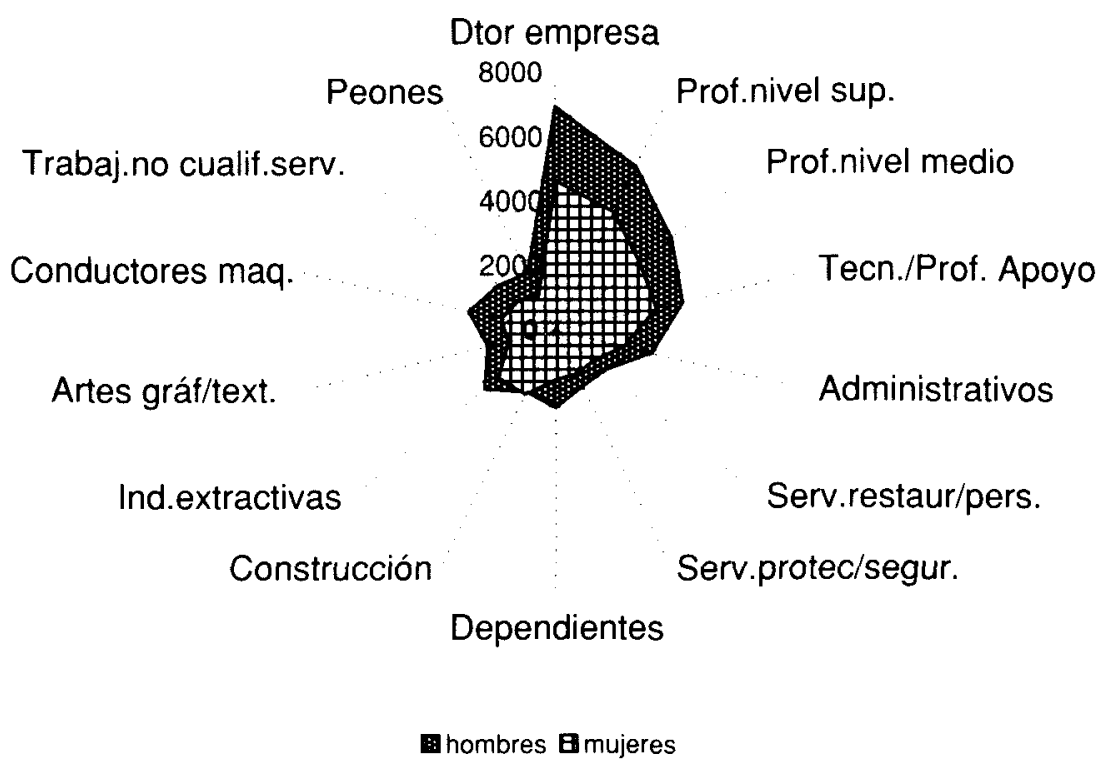

Gráfico 7. Sueldo anual por trabajador según grupos profesionales.

grupo entre jóvenes y mujeres de mayor edad. Las mujeres cualificadas con un nivel profesional medio o medio- alto representan la mano de obra femenina con mayor continuidad y estabilidad dentro del mercado de trabajo, afectándole en menor grado su estado civil. Este tipo es el que está modificando las tendencias de la actividad femenina en los últimos años, siendo el grupo que ha experimentado un mayor crecimiento, aunque sigue siendo un grupo en minoría y centrado en un reducido número de ocupaciones del sector servicios, de tipo tradicional, como son la sanidad, la educación y el sector público.

Las mujeres jóvenes sin cualificar suponen el grupo mayoritario dentro de la población activa femenina y su baja preparación les lleva a ocupar puestos poco cualificados del sector industrial o de los servicios. Las mujeres de edad relativamente alta sin cualificar suponen en torno al $25 \%$, acceden al trabajo de forma temporal para obtener una ayuda familiar, y en algunos casos trabajan como autónomos en la agricultura, en el comercio, o en la hostelería. En ambos casos, el estado civil y el nivel económico tienen una gran incidencia sobre su situación de actividad o inactividad. 


\section{DIFERENCIACIÓN ESPACIAL DE LA ACTIVIDAD E INACTIVIDAD FEMENINA.}

La heterogeneidad en la propensión al trabajo de la mujer como resultado de sus características de edad, estado civil, nivel cultural, social, económico, incluso según la profesión de su marido en las mujeres casadas, tiene diferente incidencia en las distintas regiones, produciéndose una localización geográfica desigual de la situación laboral femenina en nuestro país.

Las propias diferencias regionales en las condiciones de producción y en el ritmo de cambio social, se traducen en diferencias sensibles en los valores relacionados con la posición social de la mujer y con su trabajo intra y extradoméstico, determinando en gran manera su conducta. La ideología de años atrás, que defendía la familia y el mantenimiento de la mujer casada en el hogar, ha cambiado de forma general aunque en distinto grado.

La población inactiva femenina, según podemos ver en los mapas de distribución de la inactividad, alcanza tasas muy elevadas en las provincias del interior, superando el $70 \%$ en provincias como Zamora, Ávila, Ciudad Real, Guadalajara, Cuenca y Teruel. Por el contrario, Gerona y Lugo son las provincias con menor tasa de inactividad femenina, provincias en las que es de destacar en este año la contratación de mujeres con estudios superiores en número muy superior al de hombres. En el caso de Gerona estas contrataciones se enmarcan dentro del sector servicios, en contratos de administración y comercio, actividades que coinciden con su contexto económico; mientras que en el caso de Lugo, provincia eminentemente agrícola, es de destacar la contratación de mujeres en la sanidad y en la administración.

El contraste mayor entre la inactividad masculina y femenina se produce en las provincias de Zamora (donde en ambos casos hay una alta tasa de inactividad), y en Valladolid, Toledo, Ciudad Real y Cádiz donde esta tasa tiene sentido contrario para los dos sexos.

Relacionando las tasas de actividad, empleo y paro por Comunidades Autónomas y por provincias, que puede apreciarse en los mapas de población activa femenina, con la media nacional en ambos sexos, se corrobora la situación laboral de la mujer descrita en anteriores apartados:

- En todos los grupos de edad y en todas las Comunidades Autónomas, en 1996 continua la situación de años anteriores: el porcentaje de población masculina ocupada es mayor que el de la femenina. La diferencia más baja entre ambas se da en los menores de 25 años, con 19 
Distribución de la diferencia de inactividad entre sexos (Año 1996)

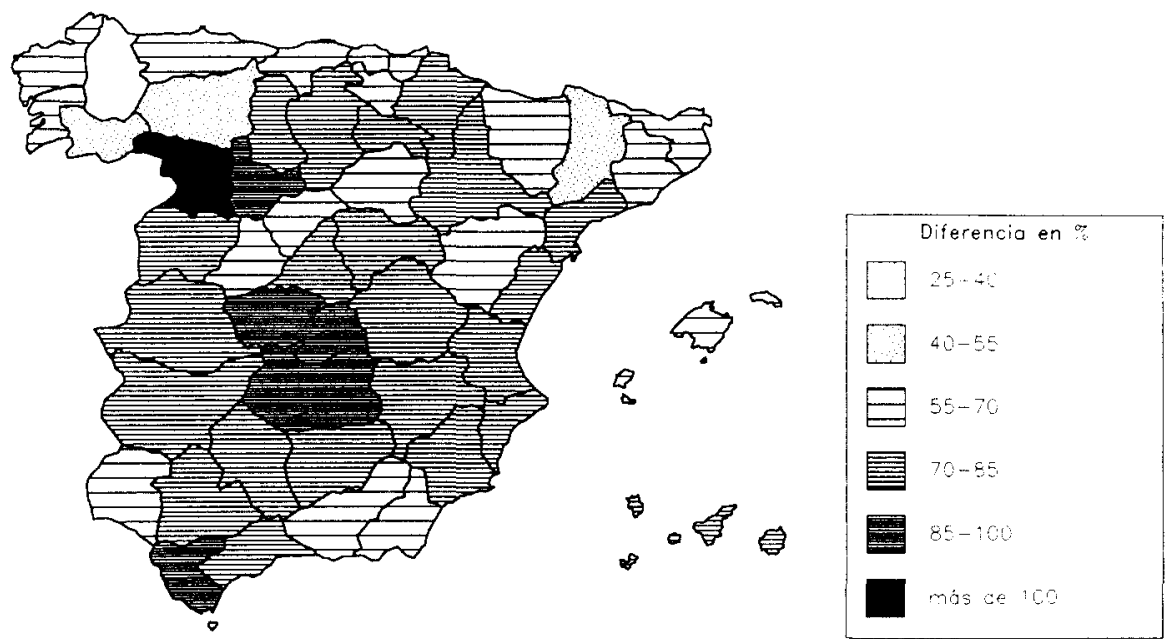

Distribución de la población inactiva femenina (Año 1996)

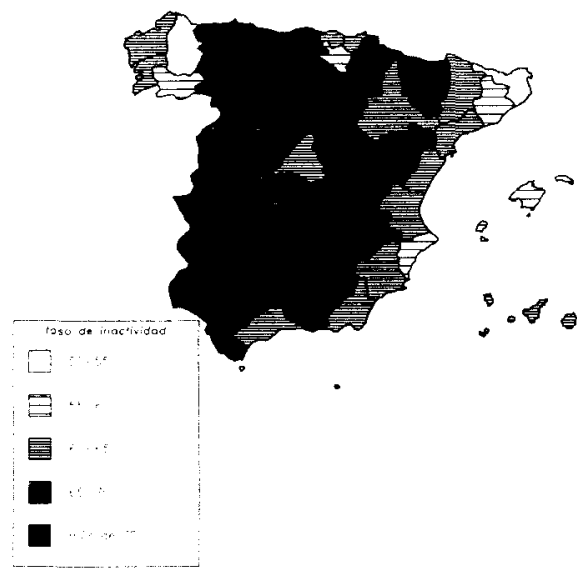

Distribución de la población inactiva masculina (Año 1996) 
La incorporación al mercado laboral de la mujer inactiva: su distribución en España...

Distribución de la población activa femenina (Año 1996)

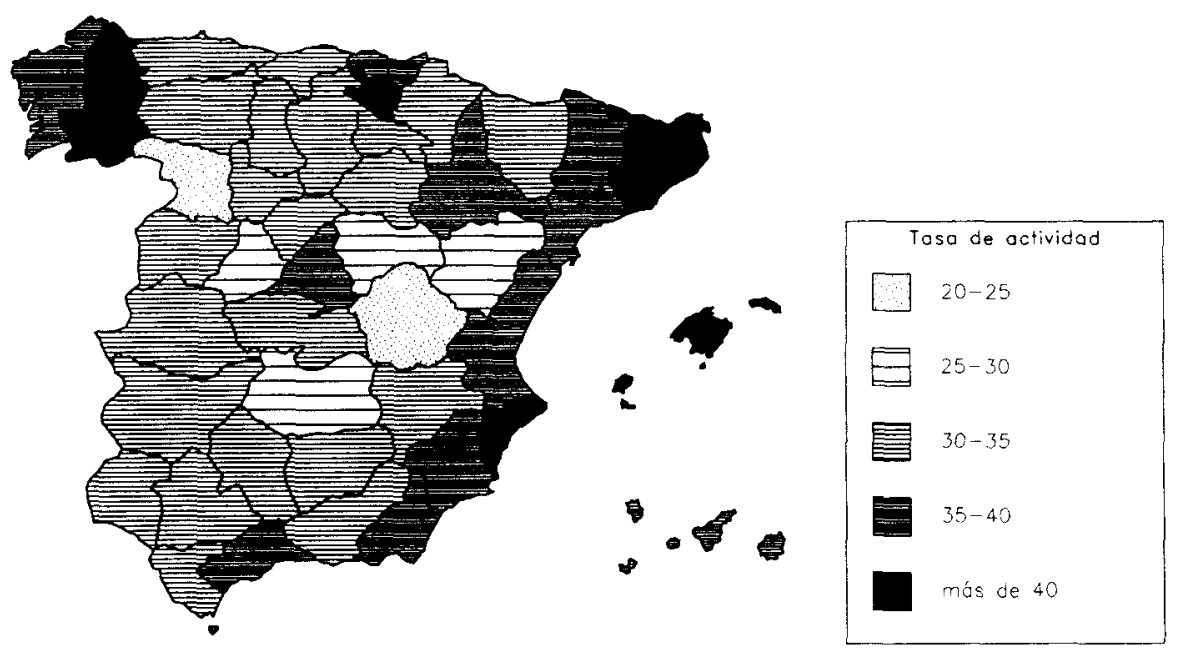

Distribución de la población femenina en paro (Año 1996)

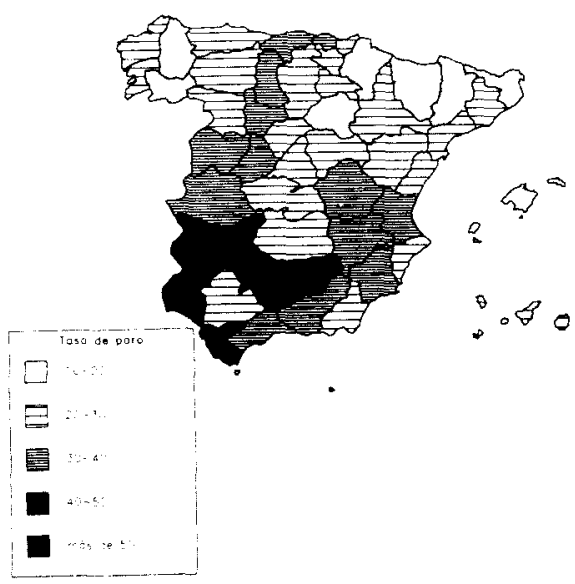

Distribución del empleo femenino

(Año 1996)

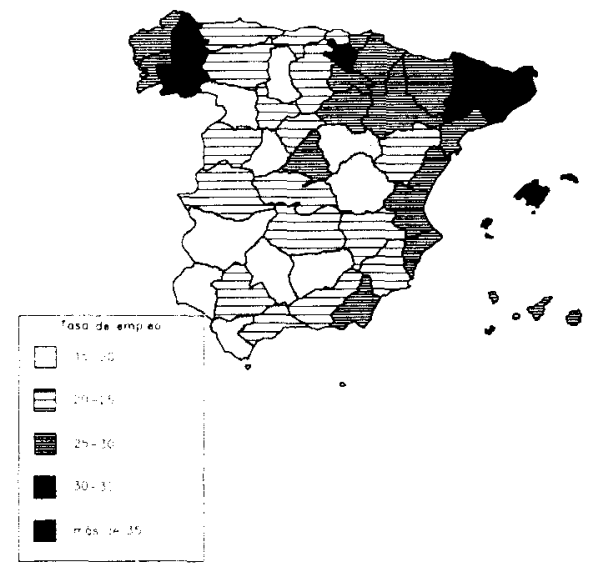


puntos porcentuales a favor de los hombres. La menor diferencia en la ocupación entre hombres y mujeres se da en Galicia (39\% de mujeres y $61 \%$ de hombres) mientras que la mayor diferencia se produce en Extremadura, con una diferencia entre ambos de un $41 \%$.

- En ninguna provincia la tasa de actividad femenina alcanza la media nacional total, y la tasa de empleo femenino sólo supera la media nacional en Gerona, en cambio, el paro femenino supera la media nacional en el $78 \%$ de las provincias, quedando sólo el paro por debajo en Lérida (13.4), Soria (15.1) Gerona (16.6), Navarra (17.9), Baleares (18.5), Lugo (18.5), Orense (19.6), Huesca (19.6), Castellón (20.5), Tarragona (20.7), y La Rioja (21.2).

- En la distribución de la actividad femenina podriamos hablar de un predominio de la periferia Este y Norte (ver mapas), que en unos casos es coincidente con la tendencia de la tasa de actividad media nacional y en otras adquieren una significativa matización. Entre las Comunidades que desde 1993 a 1996 se mantienen por encima de la tasa nacional de actividad, las islas Baleares presentan la mayor tasa de actividad a lo largo de todo este período de tiempo, con unos 4 puntos por encima de la nacional, y es la tercera provincia tanto en cuanto a población activa femenina como de empleo femenino, quedando la posición de la actividad y empleo masculino en décimo y cuarto lugar respectivamente.

Cataluña sigue a Baleares con cerca de 3,5 puntos por encima de la media nacional y también presenta una alta tasa de actividad femenina, no en vano Gerona ocupa el primer lugar tanto en actividad como en empleo femenino, y Barcelona y Tarragona el séptimo y octavo lugar del empleo femenino respectivamente. Lo mismo podemos decir de la Comunidad de Madrid, que ha tenido una tendencia positiva de crecimiento de 3,2 puntos respecto a 1993, superando también su tasa de actividad y empleo la media nacional.

La Comunidad Valenciana, pese a experimentar un descenso de la actividad en 1996 respecto a 1993, sigue por encima de la media nacional en todas sus provincias, quedando Valencia, en relación con el empleo, por debajo de la media femenina.

Galicia, comunidad donde tiene gran peso la agricultura, pese a que presenta en 1996 un descenso en su tasa de actividad respecto a 1993, es una Comunidad que tiene gran importancia en el empleo femenino, pues excepto en La Coruña, donde la tasa de actividad femenina queda por debajo de la media nacional, aunque no su empleo, las demás provincias superan esa media tanto en actividad como en empleo, es más, Lugo es la segunda provincia española en cuanto a actividad y empleo femenino, y Orense la sexta y cuarta respectivamente. 
Finalmente, en el País Vasco, Álava ocupa un puesto destacado en cuanto a actividad y empleo femenino se refiere, lo mismo que Guipúzcoa, no así Vizcaya que queda algo por debajo de la media nacional.

Analizando las situaciones de empleo y paro dentro de esta población activa, se puede establecer, a grandes rasgos, una clara diferenciación entre el Nor-noreste y el sur. Si bien el paro femenino es superior al masculino en todas las provincias, destaca especialmente en la mitad sur del país. Las tasas más altas del paro femenino siguen la distribución del paro en general, situado espacialmente y con valores superiores a la media en Andalucia $(31,9 \%)$, Extremadura $(30,8 \%)$, Ceuta y Melilla $(29,08 \%)$, destacando también algunas provincias de Castilla-León y Castilla-La Mancha. Navarra permanece con la tasa más baja de paro durante todos estos años, situándose en 1996 en algo más de 10 puntos por debajo de la nacional, y Baleares resulta ser la segunda Comunidad del territorio con menor tasa de paro.

Reforzando esta situación, la economía irregular tiene mayor incidencia en las comunidades que presentan mayores tasas de paro, mayor peso relativo de la agricultura, mayor presencia de la industria manufacturera y de bienes de consumo, mayor incidencia turística, y menores niveles de población activa oficial. Por el contrario, muestra menor incidencia en Comunidades que presentan mayor concentración industrial y mayor presencia del sector público. Las Comunidades que presentaban un porcentaje de empleo irregular sobre el total de la ocupación, superior al $25 \%$, eran Murcia $(>35 \%)$, Castilla-La Mancha $(>35 \%)$, Andalucía $(>35 \%)$, Extremadura ( $>30 \%$ ), Galicia ( $>30 \%$ ), País Vasco, Cataluña, Canarias, y Castilla-León.

- Por sectores económicos, más del $61 \%$ de los ocupados están en el sector servicios, con un $45,4 \%$ de mujeres en él. En 1996, el 48,5\% de los ocupados en este sector se concentraban en las Comunidades Autónomas de Cataluña (16,8\%), Madrid (15,9\%), y Andalucía (15,7\%). Entre las provincias que destacan en este sector, en números absolutos, las mujeres ocupadas en servicios son superiores a los hombres en todas las provincias catalanas y en Almería, y, además, en todo el País Vasco, Baleares, Valencia, Castellón, Cantabria, Navarra, La Riaja, Huesca, y Orense.

- En la industria, la mujer activa supone un 25,9\%, destacando en las provincias de Barcelona, Madrid, Alicante y Valencia. En el sector agrario, donde supone el $32,06 \%$ de la población activa, tiene su mayor representación en Galicia, donde ocupa el 50,67\% del sector, y en Andalucía el $37,32 \%$, en la Comunidad Valenciana el $19,8 \%$ y en Castilla-León igualmente el $19,8 \%$. 
- El sector de la construcción, donde tiene muy baja representación la mujer (un 5,8\% del total nacional) es prioritario en Barcelona, Madrid, donde alcanza la mayor representación, y Valencia.

- Si se analizan las contrataciones, según la información del INEM, en 1996, a escala nacional, las mujeres representan sólo el $37,8 \%$ de éstas. Las Comunidades que presentan unos índices en contratación de mujeres superiores a la media nacional son las de Aragón, Cataluña, Madrid, País Vasco y Navarra, siendo esta última la que ocupa el primer puesto; Comunidades que no son precisamente las que han tenido un crecimiento mayor de contrataciones entre 1993 y 1996 -Andalucia $(130,4 \%)$, Extremadura $(106,5 \%)$, País Vasco $(98,5 \%)$ y Murcia $(90,8 \%)$ - Esto no resulta relevante si tenemos en cuenta que precisamente Andalucía, Extremadura y Baleares son las Comunidades que realizan mayor número de contratos eventuales.

En contraposición, los porcentajes más bajos de contratación de mujeres se registran en Extremadura, Melilla, Andalucía, Castilla-La Mancha y Ceuta, coincidentes sólo en un caso con las Comunidades que han experimentado un crecimiento menor: Ceuta $(38,2 \%)$, Castilla-La Mancha $(52,6 \%)$ y Navarra $(58,1 \%)$. En estas Comunidades, además, los contratos por obra y servicio son mayoritarios (Castilla-La Mancha, Melilla, Asturias, Castilla- León, Galicia y Madrid con niveles superiores al 32\%); y los contratos a tiempo parcial tienen bastante importancia en Melilla y Madrid con un $23,7 \%$ y un $23,2 \%$ respectivamente. Los contratos de interinidad destacan en Ceuta y País Vasco con el $15,7 \%$ y $12,3 \%$ respectivamente).

Según puede apreciarse en el cuadro $n^{\circ} 4$, es generalizado el incremento de los contratos realizados a mujeres en todas las provincias, aunque no debemos olvidar en estas cifras que ocho de cada diez contratos son eventuales por circunstancias de la producción, de obra y servicio, o contratos a tiempo parcial, contratos que tienen la mayor representatividad entre todos los realizados, ya que suponen el $80,2 \%$ del total. En resumen, si bien el incremento de los contratos es una constante, hay que tener en cuenta que un elevado número consiste en contratos de condiciones poco estables. Por ejemplo, Andalucía que es la Comunidad que más ha incrementado su número de contratos, en un 130,4\%, ha realizado en 1996 una contratación eventual y a tiempo parcial del $54,8 \%$; lo mismo ocurre con Extremadura, cuyo incremento ha sido del $106,5 \%$ pero que sus contratos eventuales $y$ parciales suponen el $54,3 \%$ de la contratación; igualmente, Madrid, que aunque sólo ha subido un $70,6 \%$ sus contratos es la tercera Comunidad en volumen de contratación, tiene entre contratos eventuales, de obra y servicio y a tiempo parcial el 76\% de los contratos realizados en el año 1996. 
Población femenina activa en el sector agrario (Año 1996)

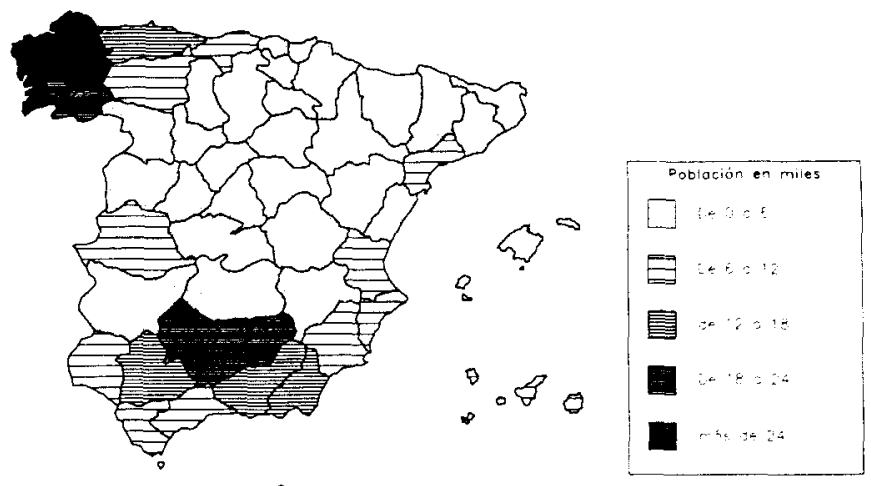

Población activa femenina en el sector industrial (Año 1996)

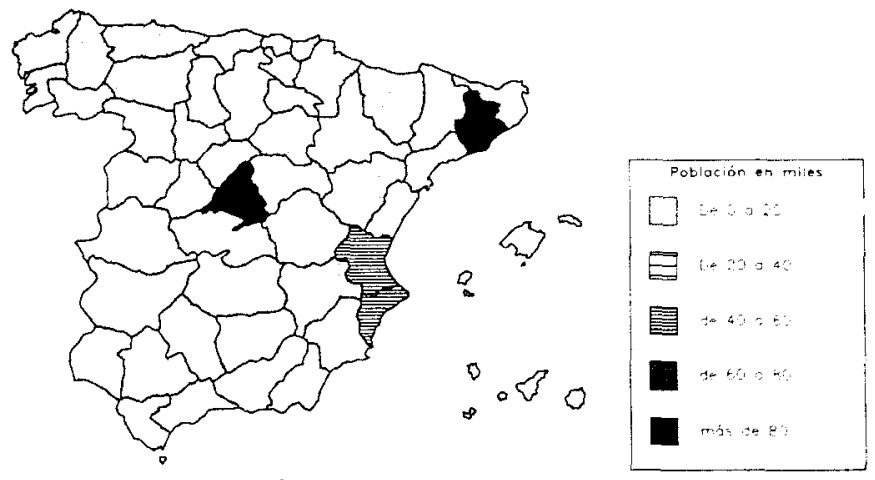

Población activa femenina en el sector servicios (Año 1996)

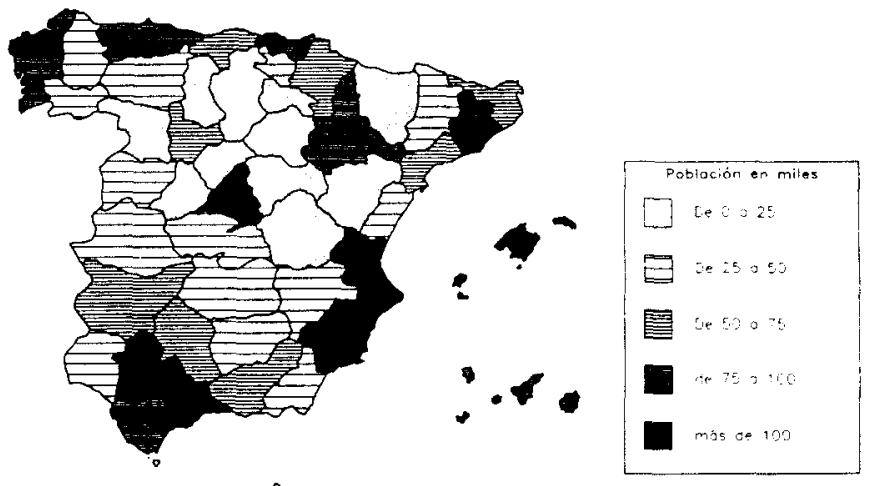


Cuadro 4. Porcentaje de mujeres demandantes de empleo (1) $y$ de mujeres contratadas (2)

\begin{tabular}{|c|c|c|c|c|c|c|}
\hline & $\begin{array}{c}1992 \\
\text { (1) }\end{array}$ & (2) & $\begin{array}{c}1994 \\
(1)\end{array}$ & (2) & $\begin{array}{c}1996 \\
\text { (1) }\end{array}$ & (2) \\
\hline \multicolumn{7}{|l|}{ ANDALUCÍA } \\
\hline Almería & 51.05 & 32.20 & 49.64 & 39.66 & 50.62 & 39.88 \\
\hline Cádiz & 45.80 & 22.83 & 45.37 & 24.05 & 45.37 & 25.38 \\
\hline Córdoba & 54.96 & 25.46 & 54.91 & 36.08 & 54.09 & 39.86 \\
\hline Granada & 53.28 & 27.02 & 51.71 & 32.92 & 50.88 & 36.78 \\
\hline Huelva & 52.18 & 13.69 & 51.24 & 37.08 & 51.17 & 36.66 \\
\hline Jaén & 47.75 & 22.09 & 52.84 & 23.87 & 52.40 & 31.73 \\
\hline Málaga & 48.87 & 33.80 & 48.32 & 36.06 & 48.99 & 36.66 \\
\hline $\begin{array}{l}\text { Sevilla } \\
\text { ARAGÓN }\end{array}$ & 54.55 & 24.86 & 52.70 & 33.75 & 52.53 & 34.62 \\
\hline Huesca & 58.70 & 41.67 & 59.22 & 38.42 & 59.09 & 42.64 \\
\hline Teruel & 55.43 & 30.75 & 56.25 & 32.71 & 58.00 & 37.89 \\
\hline Zaragoza & 58.53 & 40.68 & 57.28 & 39.80 & 59.67 & 41.89 \\
\hline ASTURIAS & 58.21 & 33.27 & 53.57 & 36.24 & 53.94 & 38.55 \\
\hline $\begin{array}{l}\text { BALEARES } \\
\text { C.-LA MANC }\end{array}$ & 53.59 & 40.34 & 54.29 & 41.50 & 55.62 & 42.40 \\
\hline Albacete & 51.07 & 30.41 & 49.77 & 30.63 & 50.96 & 31.95 \\
\hline Ciudad Real & 46.19 & 24.37 & 45.66 & 24.34 & 45.94 & 25.47 \\
\hline Cuenca & 49.62 & 25.57 & 47.54 & 29.37 & 48.68 & 33.63 \\
\hline Guadalajara & 57.06 & 31.14 & 54.66 & 28.88 & 55.51 & 32.37 \\
\hline $\begin{array}{l}\text { Toledo } \\
\text { CASTILLA-LI }\end{array}$ & 51.55 & 27.06 & 50.14 & 29.27 & 50.92 & 33.43 \\
\hline Ávila & 54.74 & 22.72 & 52.44 & 30.44 & 53.24 & 32.26 \\
\hline Burgos & 56.41 & 31.51 & 56.00 & 36.03 & 58.03 & 41.24 \\
\hline León & 53.14 & 27.10 & 53.58 & 30.77 & 56.12 & 33.74 \\
\hline Palencia & 54.24 & 32.12 & 53.94 & 37.13 & 54.79 & 40.47 \\
\hline Salamanca & 56.73 & 27.45 & 55.74 & 31.62 & 55.81 & 36.27 \\
\hline Segovia & 59.46 & 32.12 & 59.98 & 38.30 & 59.82 & 41.99 \\
\hline Soria & 58.92 & 29.92 & 57.71 & 40.71 & 61.37 & 43.34 \\
\hline Valladolid & 56.61 & 31.91 & 54.49 & 35.58 & 55.65 & 36.80 \\
\hline \multicolumn{7}{|l|}{ CANARIAS } \\
\hline Las Palmas & 50.04 & 40.09 & 50.41 & 39.28 & 53.21 & 38.97 \\
\hline Tenerife & 48.95 & 36.40 & 49.03 & 39.84 & 51.37 & 38.70 \\
\hline CANTABRIA & 48.87 & 35.65 & 49.61 & 35.99 & 48.05 & 35.73 \\
\hline \multicolumn{7}{|l|}{ CATALUÑA } \\
\hline Barcelona & 53.94 & & 51.24 & 41.29 & 53.28 & 43.50 \\
\hline Gerona & 54.97 & 42.76 & 53.93 & 43.59 & 54.95 & 44.26 \\
\hline Lérida & 59.79 & 39.74 & 56.14 & 40.74 & 56.59 & 41.44 \\
\hline $\begin{array}{l}\text { Tarragona } \\
\text { C. VALENCl }\end{array}$ & 52.00 & 37.19 & 50.36 & 37.23 & 52.36 & 39.12 \\
\hline Alicante & 50.78 & 37.94 & 50.11 & 37.58 & 50.93 & 38.19 \\
\hline
\end{tabular}


Cuadro 4. Porcentaje de mujeres demandantes de empleo (1) $y$ de mujeres contratadas (2) (continuación)

\begin{tabular}{lcccccc}
\hline & $\begin{array}{c}1992 \\
(1)\end{array}$ & $(2)$ & $\begin{array}{c}1994 \\
(1)\end{array}$ & $(2)$ & $\begin{array}{c}1996 \\
(1)\end{array}$ & $(2)$ \\
\hline Castellón & 55.00 & 34.95 & 56.60 & 35.88 & 56.65 & 38.91 \\
Valencia & 55.91 & 35.17 & 54.69 & 35.73 & 56.06 & 37.57 \\
EXTREMADURA & & & & & & \\
Badajoz & 45.79 & 26.27 & 44.97 & 23.48 & 44.96 & 24.58 \\
Cáceres & 49.01 & 28.22 & 47.13 & 29.82 & 46.78 & 33.42 \\
GALICIA & & & & & & \\
Coruña, La & 53.08 & 31.44 & 50.39 & 35.29 & 51.00 & 38.59 \\
Lugo & 51.75 & 26.35 & 50.02 & 28.44 & 50.37 & 43.84 \\
Orense & 50.18 & 20.64 & 51.03 & 31.71 & 51.51 & 35.61 \\
Pontevedra & 54.87 & 32.95 & 52.65 & 36.94 & 54.64 & 38.88 \\
MADRID & 59.04 & 38.71 & 54.53 & 38.71 & 55.03 & 39.52 \\
NAVARRA & 60.17 & 43.66 & 59.80 & 41.33 & 59.67 & 43.13 \\
PAíS VASCO & & & & & & \\
Álava & 57.51 & 43.19 & 56.80 & 43.22 & 59.46 & 43.17 \\
Guipúzcoa & 50.84 & 39.57 & 51.41 & 44.18 & 55.88 & 43.87 \\
Vizcaya & 50.07 & 37.07 & 48.33 & 37.75 & 50.81 & 37.72 \\
RIOJA, LA & 58.39 & 34.29 & 58.52 & 37.73 & 59.47 & 38.14 \\
CEUTA & 47.44 & 34.41 & 46.99 & 32.82 & 47.41 & 35.10 \\
MELILLA & 60.11 & 31.58 & 59.96 & 26.55 & 58.61 & 28.72 \\
\hline
\end{tabular}

Fuente: INEM. Elaboración propia.

Igualmente interesante resulta el análisis del nivel de estudios entre mujeres demandantes de empleo y contratadas, que muestra el cuadro $n^{\circ}$ $5 \mathrm{El}$ predominio en ambos casos es de estudios de nivel medio y lo más habitual es que coincida a más demanda de un nivel más contratos de dicho nivel, o que, aún habiendo mayor demanda de estudios superiores, la mayoría de los contratos queden en nivel inferior, no obstante hay casos en que no se da esta relación como ocurre en Asturias, Salamanca, y Soria, en los que pese a una demanda mayor de estudios medios se correspondió una mayor contratación en estudios superiores. Soria es el caso más espectacular, pues el $19,25 \%$ de los contratos a mujeres se hicieron a aquellas que tenían estudios superiores, especialmente en el área de sanidad ( 1.320 médicos y 1.063 ATS) en calidad de "otros contratos no especificados". En Salamanca se centró en empleados administrativos (1.712 mujeres) en calidad de "parcial determinado con prestación y reducción de jornada", lo mismo que en Asturias.

La distribución de la población femenina demandante de empleo a través del INEM en 1996 con mayor nivel de estudios — nivel superior y medio- 
muestra diferencias regionales notables, que van desde el $43,3 \%$ de las Baleares hasta el $23,81 \%$ de Soria, superándose el $15 \%$ en Salamanca $(21,9 \%)$, Segovia $(19,8 \%)$, Valladolid $(18,5 \%)$, Navarra $(17,6 \%)$, Huesca $(17,6 \%)$, Palencia $(16,7 \%)$, Vizcaya $(16 \%)$, Teruel $(15,8 \%)$, Madrid $(15,4 \%)$ Burgos (15,3\%), Ávila (15,1\%), y Guipúzcoa (15\%). Estas provincias, debido a esta mayor instrucción de la mujer, deberían tener menor tasa de paro y mayor de empleo femenino, y aunque así es en la mayoría no lo es en su totalidad, como son los casos de Salamanca, Valladolid, Vizcaya, y Ávila.

Según la edad, los contratados menores de 25 años alcanzan los porcentajes más altos en Aragón, Baleares, Cataluña, Madrid, Murcia, Navarra y la Rioja, en donde superan el $37 \%$. Por el contrario Andalucía, Asturias, Extremadura y Ceuta no suponen el $29 \%$. Los contratos entre 25 y 45 años tienen especial relevancia en Extremadura y Andalucia, en donde alcanzan el $15,7 \%$ y el $14,7 \%$ respectivamente, en ambos casos a costa del grupo de los más jóvenes. Del resto de las Comunidades sólo Castilla-La Mancha (12,6\%), Comunidad Valenciana (11,6\%) y Galicia $(11,5 \%)$ superan la media nacional.

Cuadro 5. Nivel de estudios de las mujeres demandantes/contratadas en empleos a través del INEM

\begin{tabular}{lccc}
\hline & E. superiores & E. medios & índice $E$ \\
\hline ANDALUCíA & & & \\
Almería & $4.07 / 2.40$ & $5.91 / 4.42$ & $1.14 / 1.09$ \\
Cádiz & $2.21 / 1.49$ & $4.70 / 3.85$ & $1.09 / 1.06$ \\
Córdoba & $2.48 / 1.62$ & $4.04 / 2.44$ & $1.08 / 0.99$ \\
Granada & $4.58 / 3.53$ & $5.81 / 4.93$ & $1.14 / 1.10$ \\
Huelva & $2.04 / 1.39$ & $3.91 / 2.55$ & $1.07 / 1.05$ \\
Jaén & $3.09 / 1.50$ & $5.27 / 3.06$ & $1.11 / 1.05$ \\
Málaga & $2.97 / 1.80$ & $4.22 / 3.72$ & $1.10 / 1.07$ \\
Sevilla & $3.56 / 1.97$ & $3.45 / 2.31$ & $1.10 / 1.06$ \\
ARAGÓN & & & \\
Huesca & $5.59 / 6.24$ & $12.08 / 9.37$ & $1.23 / 1.21$ \\
Teruel & $4.83 / 3.50$ & $10.98 / 6.92$ & $1.20 / 1.13$ \\
Zaragoza & $6.83 / 3.87$ & $8.62 / 5.99$ & $1.22 / 1.13$ \\
ASTURIAS & $6.48 / 7.08$ & $8.29 / 6.91$ & $1.21 / 1.21$ \\
BALEARES & $1.94 / 0.40$ & $2.39 / 1.35$ & $1.06 / 1.02$ \\
CANARIAS & & & \\
Las Palmas & $2.95 / 1.57$ & $4.38 / 2.78$ & $1.10 / 1.05$ \\
Tenerife & $3.99 / 2.56$ & $3.71 / 4.54$ & $1.11 / 1.09$ \\
C.-LA MANCHA & & & \\
Albacete & $3.42 / 2.03$ & $4.40 / 3.56$ & $1.11 / 1.07$ \\
Ciudad Real & $4.18 / 4.68$ & $4.88 / 7.49$ & $1.13 / 1.16$ \\
\hline
\end{tabular}


La incorporación al mercado laboral de la mujer inactiva: su distribución en España...

Cuadro 5. Nivel de estudios de las mujeres demandantes/contratadas en empleos a través del INEM (continuación)

\begin{tabular}{|c|c|c|c|}
\hline & E. superiores & E. medios & Índice $E$ \\
\hline Cuenca & $5.19 / 5.33$ & $8.10 / 8.10$ & $1.18 / 1.15$ \\
\hline Guadalajara & $7.55 / 4.77$ & $5.81 / 3.77$ & $1.20 / 1.13$ \\
\hline Toledo & $4.57 / 2.69$ & $4.08 / 3.17$ & $1.13 / 1.08$ \\
\hline \multicolumn{4}{|c|}{ CASTILLA-LEÓN } \\
\hline Ávila & $6.32 / 2.83$ & $8.82 / 4.62$ & $1.14 / 1.10$ \\
\hline Burgos & $6.16 / 4.04$ & $9.20 / 6.21$ & $1.21 / 1.14$ \\
\hline León & $5.62 / 4.25$ & $9.13 / 6.88$ & $1.20 / 1.15$ \\
\hline Palencia & $5.50 / 6.20$ & $11.24 / 8.60$ & $1.22 / 1.21$ \\
\hline Salamanca & $10.91 / 9.54$ & $11.01 / 8.18$ & $1.32 / 1.27$ \\
\hline Segovia & $11.29 / 4.25$ & $8.52 / 3.85$ & $1.31 / 1.12$ \\
\hline Soria & $8.31 / 19.25$ & $15.5 / 17.64$ & $1.32 / 1.51$ \\
\hline Valladolid & $8.83 / 4.82$ & $9.73 / 5.66$ & $1.27 / 1.15$ \\
\hline Zamora & $5.46 / 8.67$ & $8.46 / 11.48$ & $1.19 / 1.28$ \\
\hline CANTABRIA & $5.39 / 3.80$ & $7.88 / 5.19$ & $1.18 / 1.12$ \\
\hline \multicolumn{4}{|l|}{ CATALUÑA } \\
\hline Barcelona & $3.69 / 3.18$ & $3.24 / 6.02$ & $1.10 / 1.11$ \\
\hline Gerona & $2.26 / 2.39$ & $2.74 / 3.73$ & $1.07 / 1.08$ \\
\hline Lérida & $4.09 / 3.29$ & $7.19 / 7.69$ & $1.15 / 1.14$ \\
\hline Tarragona & $2.49 / 3.05$ & $3.45 / 6.49$ & $1.08 / 1.12$ \\
\hline \multicolumn{4}{|c|}{ C. VALENCIANA } \\
\hline Alicante & $3.33 / 1.61$ & $3.81 / 2.29$ & $1.10 / 0.97$ \\
\hline Castellón & $5.53 / 2.86$ & $5.25 / 3.54$ & $1.16 / 1.09$ \\
\hline Valencia & $5.36 / 2.69$ & $5.20 / 3.67$ & $1.15 / 1.09$ \\
\hline \multicolumn{4}{|c|}{ EXTREMADURA } \\
\hline Badajoz & $2.77 / 0.89$ & $5.61 / 3.37$ & $1.11 / 1.04$ \\
\hline Cáceres & $7.38 / 7.11$ & $6.09 / 5.41$ & $1.20 / 1.19$ \\
\hline Lugo & $5.24 / 8.44$ & $7.15 / 20.47$ & $1.17 / 1.37$ \\
\hline Orense & $4.27 / 6.75$ & $5.23 / 8.94$ & $1.13 / 1.22$ \\
\hline Pontevedra & $3.99 / 4.79$ & $4.76 / 6.47$ & $1.13 / 1.05$ \\
\hline MADRID & $10.12 / 4.32$ & $5.32 / 3.22$ & $1.25 / 1.11$ \\
\hline MURCIA & $4.96 / 1.84$ & $6.33 / 4.54$ & $1.03 / 1.08$ \\
\hline NAVARRA & $8.33 / 5.43$ & $9.23 / 6.60$ & $1.25 / 1.06$ \\
\hline \multicolumn{4}{|l|}{ PAÍS VASCO } \\
\hline Álava & $8.51 / 11.44$ & $6.48 / 13.2$ & $1.23 / 1.46$ \\
\hline Guipúzcoa & $8.47 / 7.19$ & $6.56 / 7.19$ & $1.23 / 1.21$ \\
\hline Vizcaya & $9.87 / 5.17$ & $6.19 / 4.59$ & $1.25 / 1.14$ \\
\hline RIOJÁ, LA & $6.65 / 3.84$ & $8.09 / 4.01$ & $1.18 / 1.11$ \\
\hline
\end{tabular}

\section{CONCLUSIONES}

La tasa de inactividad de la mujer en España sigue siendo elevada y por encima de los países de nuestro entorno económico, aunque en los 
años 90 la mujer se ha incorporado significativamente al mercado laboral. Al mismo tiempo, el paro sigue afectando a la mujer en un notorio mayor grado que a los hombres.

Es sobre todo su mayor grado de instrucción y el mayor nivel de estudios que alcanza,lo que está haciendo cambiar el número de mujeres que trabajan y su categoría profesional. Es patente el aumento de su presencia en ocupaciones de alto nivel, sobre todo en cuanto a directivos de la administración pública (de 21.400 en 1990 a 334.600 en 1996) y profesionales, técnicos y similares (de 633.700 en el año 1990 a 1.022 .000 en 1996), habiendo descendido su número como empleadas administrativas, personal de servicios y en el comercio. Su situación profesional también está cambiando, ascendiendo su papel de empleadora (de 64.800 en 1990 a 104.300 en 1996) y en asalariados, disminuyendo su situación en «ayudas familiares", aunque sigue siendo una situación con elevada presencia.

A pesar de este giro laboral, la mujer se encuentra todavía centrada en determinadas profesiones, tradicionalmente femeninas, y discriminada en su remuneración. Por otro lado, este cambio se centra sobre todo en un determinado tipo de mujeres jóvenes que han modificado las características tradicionales de la mujer trabajadora, pero sigue habiendo todavía un importante grupo, mayoritario, al que en poco afectan las situaciones del cambio.

Se aprecian significativas diferencias regionales en la actividad femenina. Establecidas las correlaciones entre la tasa de actividad femenina y su tasa de empleo, de población por sectores de actividad, de edad de las mujeres demandantes de empleo y de grado de instrucción, se observa que efectivamente es el nivel de instrucción, en el contexto global del país, el que marca las diferencias en la correlación. Por Comunidades Autónomas encontramos que actividad y empleo se correlacionan excepto en Levante, Navarra, Rioja y Cantabria; que la actividad se relaciona con los sectores secundario y terciario de actividad prioritarios en cada caso, quedando el sector primario correlacionado tan sólo en Levante y en las islas. Igualmente, la actividad se relaciona con la población más joven excepto en Castilla-León, Andalucía, País Vasco y Galicia; y con el nivel de estudios, marcándose las diferencias sobre todo en relación con los estudios superiores, con los que no se guarda correlación en Galicia, Aragón, Castilla-León y Andalucía.

\section{BIBLIOGRAFÍA}

INE. Encuesta de Población Activa. Resumen anual 1996.

INE. Encuesta Salarial 1995. 
INEM (1998) «Información sobre Mercado de Trabajo. Resumen de datos del Observatorio Ocupacional. 1996". Madrid. Ministerio de Trabajo y Asuntos Sociales.

Miguel CASTAÑo, Carmen de (1988) "La participación femenina en la actividad económica". Seminario mujer e igualdad de oportunidades en el trabajo. Santander sept 1987.

O.C.D.E. (1986) "La integración de la mujer en la economla". Informes de la O.C.D.E. Madrid. Ministerio de Trabajo y Seguridad Social.

SALLĖ, $M^{z}$ Angeles \& CASAS, Jose Ignacio (1987) "Efectos de la crisis económica sobre el trabajo de las mujeres". Madrid. Instituto de la Mujer. Ministerio de cultura. 